The University of San Francisco

USF Scholarship: a digital repository @ Gleeson Library | Geschke Center

Spring 5-17-2019

\title{
Standardizing Mammogram Screening in Primary Care: Integrating an Evidence Based Approach
}

Lacrisha Go

ljgo@dons.usfca.edu

Follow this and additional works at: https://repository.usfca.edu/dnp

Part of the Family Practice Nursing Commons

\section{Recommended Citation}

Go, Lacrisha, "Standardizing Mammogram Screening in Primary Care: Integrating an Evidence Based Approach" (2019). Doctor of Nursing Practice (DNP) Projects. 175.

https://repository.usfca.edu/dnp/175

This Project is brought to you for free and open access by the Theses, Dissertations, Capstones and Projects at USF Scholarship: a digital repository @ Gleeson Library | Geschke Center. It has been accepted for inclusion in Doctor of Nursing Practice (DNP) Projects by an authorized administrator of USF Scholarship: a digital repository @ Gleeson Library | Geschke Center. For more information, please contact repository@usfca.edu. 
Standardizing Mammogram Screening in Primary Care:

Integrating an Evidence Based Approach

Lacrisha Go, DNP(c), BSN, RN, OCN

DNP Committee Chair: Dr. Prabjot Sandhu, DNP, FNP-C, PA-C, CNL

DNP Committee Member: Dr. Jo Loomis, DNP, FNP-C, CHSE, CLC, ANLC, NCMP, CNL 


\begin{abstract}
Background: Mammogram screening for surveillance and detection of breast cancer has long been recognized as a preventative health measure in primary care for women. However, easily recognizing when to screen individual women, based on age and risk factors, lacks clear guidance and often ends in fragmented and inconsistent practices among providers.
\end{abstract}

Methods: By developing and implementing the Screening Mammogram Initiation Protocol (SMIP), the desired goals of this project were to: a) align breast cancer screening recommendations to better meet individualized patient needs in primary care utilizing best practice guidelines, b) increase the rate of breast cancer screening across various demographics, and c) create a standardized screening protocol tool that increases shared decision making based on individual risk factors. Outcome measures were reflected by an increase in provider knowledge towards female breast health counseling, an increase in rates of breast cancer screening discussions, and the successful implementation of the SMIP at a local primary care clinic in Oakland, California.

Results: Responses from the pre/post knowledge and post-implementation surveys showed improved provider understanding of the current breast cancer screening guidelines for average and high-risk females as well as $90 \%$ satisfaction utilizing the SMIP in practice. Electronic data collection after nine-weeks showed an eight percent increase (64\% to $72 \%)$ in referrals for women aged 40-49 eligible for breast cancer screening and seven percent increase (73\% to $80 \%$ ) in referrals for women aged 50-59 eligible for breast cancer screening.

Conclusion: This evidence-based change in practice project ultimately improved the quality of care by enhancing preventative health delivery, contribute to increased screening, and likely impact breast cancer morbidity, and mortality rates. 
Keywords: Breast cancer, breast cancer screening, mammography, age factors, risk factors, benefits, and harms. 


\section{Table of Contents}

\section{Section I: Title and Abstract}

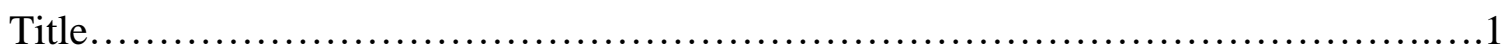

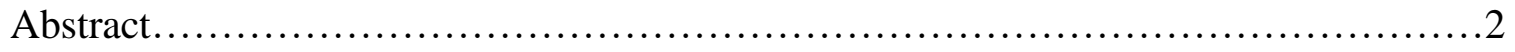

Table of Contents.............................................................

\section{Section II: Introduction}

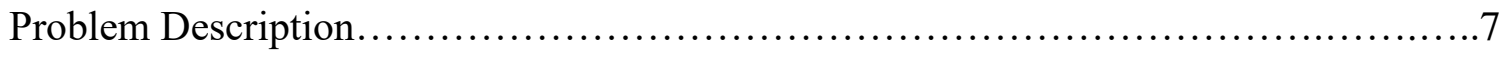

Overview of the Current Guidelines....................................... 7

Current Practice and Insurance Coverage................................. 13

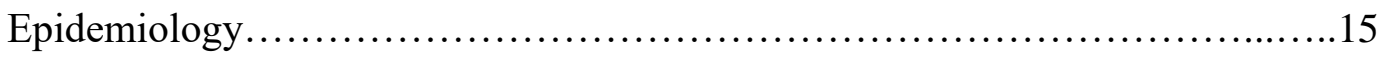

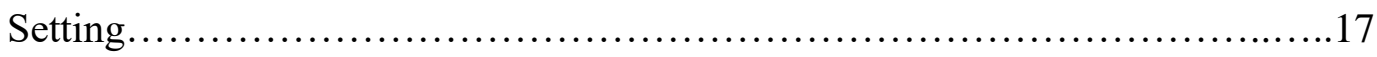

Available Knowledge......................................................19

Review of Literature................................................21

Disadvantages to Breast Cancer Screening with Mammography (for

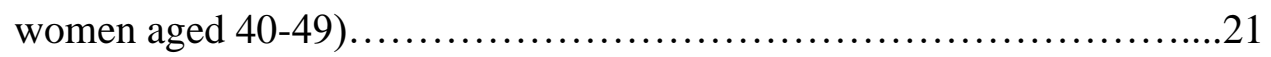

False-Positives.......................................21

Overdiagnosis.........................................23

Psychological Impact....................................24

Mammography Radiation Risk.............................24

Advantages to Breast Cancer Screening with Mammography (for women

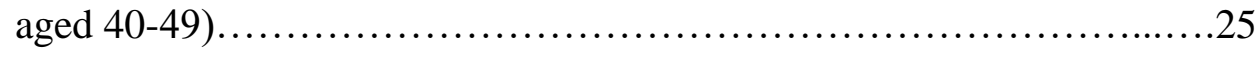

Earlier Diagnosis Stage..................................25

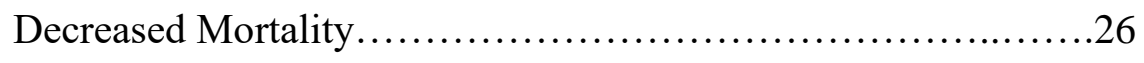


Lives Saved/Potential Years of Life Gained..................26

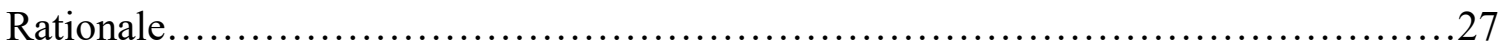

Theoretical/Conceptual Frameworks......................................27

Specific Aim............................................................29

\section{Section III: Methods}

Context.......................................................................

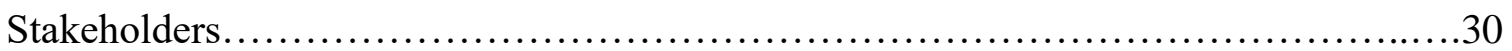

Interventions............................................................ 31

Gap Analysis............................................................. 32

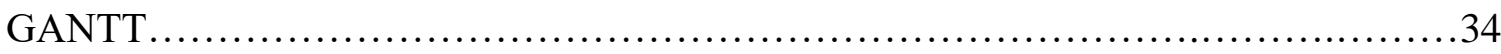

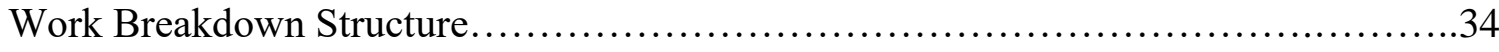

SWOT Analysis........................................................ 34

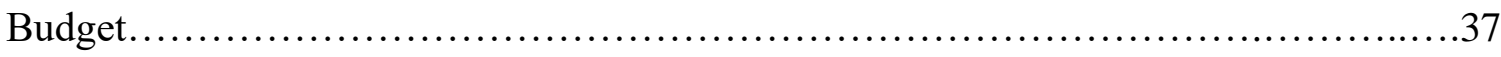

Communication Plan............................................................

Outcome Measures.......................................................... 39

Analysis.......................................................................

Ethical Considerations....................................................... 40

\section{Section IV: Results}

Results...................................................................41

\section{Section V: Discussion}

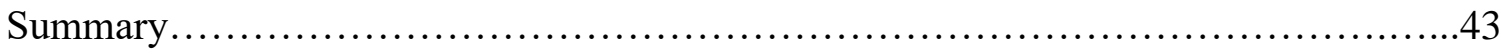

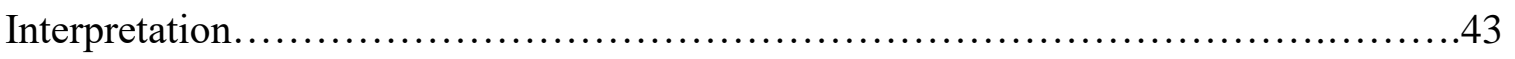

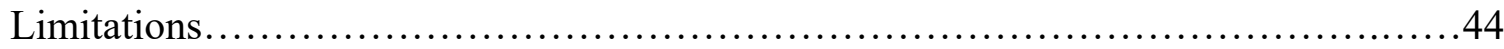


Conclusions ........................................................... 45

\section{Section VI. Other Information}

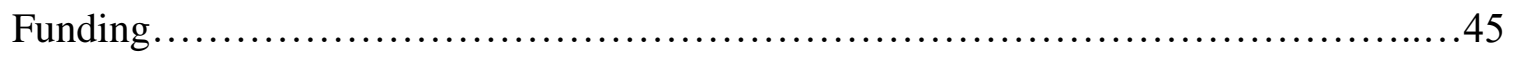

\section{Section VII. References}

References.............................................................. 46

\section{Section VIII. Appendices}

Appendix A: DNP Statement of Non-Research Determination.....................51

Appendix B: Letter of Support from Organization...............................54

Appendix C: Evaluation Table..............................................55

Appendix D: Gap Analysis Interview with NP Balkissoon........................61

Appendix E: Gap Analysis..............................................62

Appendix F: GANTT Chart...............................................63

Appendix G: Work Breakdown Structure......................................64

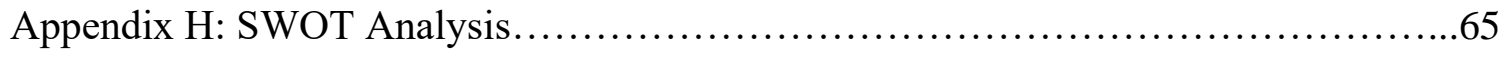

Appendix I: Budget......................................................66

Appendix J: Communication Matrix........................................68

Appendix K: Screening Mammogram Initiation Protocol..........................69

Appendix L: Pre-and-Post Knowledge and Project Implementation Surveys.............73

Appendix M: PowerPoint Slide Presentation.................................. 76

Appendix N: Survey Results.............................................. 78

Appendix O: I2I Tracking Results......................................... 83 


\section{Section II: Introduction}

\section{Problem Description}

In the United States, breast cancer continues to be the second most common cancer diagnosis in females, and the second leading cause of cancer death in women (ACS, 2019; Centers for Disease Control and Prevention [CDC], 2018). It is estimated, that in 2019, 268,600 new diagnoses of breast cancer will occur, and $10 \%$ of those new cases will be found in women under the age of 45 (ACS, 2019; CDC, 2018; Surveillance, Epidemiology, and End Results Program [SEER], n.d.). Of women under 45, breast cancer is most commonly found in the African American race who also experience the overall highest death rate associated with breast cancer in comparison to White, Asian, Pacific Islander, Native American, Hispanic, and NonHispanic women (Breastcancer.org, 2019; SEER, n.d.). Women with a first-degree relative (mother, sister, daughter) with history of breast cancer have a near two-fold increased risk of developing breast cancer (Breastcancer.org, 2019). The lifetime breast cancer risk for women who have a BRCA1 or BRCA2 gene mutation is $72 \%$ and $69 \%$, respectively and is more prevalent in the younger population (Breastcancer.org, 2019). One in eight women will develop breast cancer in their lifetime, $15 \%$ will have an associated first-degree relative, and 5-10\% will be related to a genetic mutation (ACS, 2019; Breastcancer.org, 2019).

\section{Overview of the Current Guidelines}

The recommendations for initiating breast cancer screening (BCS) with a mammogram, the frequency with which to continue monitoring, and the screening discontinuation age differ among reputable organizations and professional societies (Table 1).

\section{Table 1:}




\begin{tabular}{|c|c|c|c|c|}
\hline Group & $\begin{array}{l}\text { Age to Initiate } \\
\text { Mammograms }\end{array}$ & Frequency (years) & $\begin{array}{c}\text { Age to } \\
\text { Discontinue } \\
\text { Mammograms }\end{array}$ & $\begin{array}{l}\text { Shared Decision } \\
\text { Making Approach }\end{array}$ \\
\hline $\mathrm{ACOG}^{1}$ & $\begin{array}{c}40^{*} \\
\text { No later than } 50\end{array}$ & $1-2 *$ & $\begin{array}{l}75, \text { anything } \\
\text { beyond is } \\
\text { provider-patient } \\
\text { discussion }\end{array}$ & $\begin{array}{l}* \text { Recommendation for } \\
\text { initiating the BCS } \\
\text { screening process to start } \\
\text { at age } 40 . \text { The age to } \\
\text { begin mammography } \\
\text { requires an informed } \\
\text { decision based on } \\
\text { provider-patient } \\
\text { discussion about the } \\
\text { potential risks, benefits, } \\
\text { and patient } \\
\text { values/preferences. }\end{array}$ \\
\hline $\mathrm{ACR}^{2}$ & 40 & 1 & $\begin{array}{l}\text { Life expectancy } \\
<5-7 \text { years or if no } \\
\text { further } \\
\text { intervention } \\
\text { planned regardless } \\
\text { of imaging results }\end{array}$ & $\begin{array}{l}\text { Screening considerations } \\
\text { should include educating } \\
\text { women of the risks, } \\
\text { benefits, and limitations } \\
\text { of screening to help the } \\
\text { patient make an informed } \\
\text { decision. }\end{array}$ \\
\hline $\mathrm{ACS}^{3}$ & $\begin{array}{c}40-44 \\
\text { (Qualified } \\
\text { Recommendation) } \\
45 \\
\text { (Strong } \\
\text { Recommendation) }\end{array}$ & $\begin{array}{c}\text { 1: ages 40-44 if } \\
\text { starting (Qualified } \\
\text { Recommendation) } \\
\text { 1: ages 45-54 } \\
\text { (Qualified } \\
\text { Recommendation) } \\
\text { 1-2: age } \geq 55 \\
\text { (Qualified } \\
\text { Recommendation) }\end{array}$ & $\begin{array}{l}\text { Life expectancy } \\
<10 \text { years } \\
\text { (Qualified } \\
\text { Recommendation) }\end{array}$ & $\begin{array}{l}\text { A qualified } \\
\text { recommendation is } \\
\text { interpreted as the health } \\
\text { care professional will } \\
\text { provide education on the } \\
\text { different options and help } \\
\text { the patient consider their } \\
\text { values/preferences to make } \\
\text { an informed decision. }\end{array}$ \\
\hline $\mathrm{NCCN}^{4}$ & 40 & 1 & $\begin{array}{c}\text { Limited life } \\
\text { expectancy and no } \\
\text { further } \\
\text { intervention } \\
\text { planned regardless } \\
\text { of imaging results }\end{array}$ & $\begin{array}{l}\text { Recommendations for } \\
\text { screening also } \\
\text { encourages counseling } \\
\text { women on the potential } \\
\text { risks, benefits, limitations } \\
\text { of mammography, and } \\
\text { consider the patient's } \\
\text { values/preferences. } \\
\text { Annual screening offers } \\
\text { the opportunity for } \\
\text { updating BC risk } \\
\text { assessments, modifiable } \\
\text { risk reduction } \\
\text { counseling, review of } \\
\text { red-flag symptoms, and } \\
\text { option for clinical breast } \\
\text { exams. }\end{array}$ \\
\hline
\end{tabular}




\begin{tabular}{|c|c|c|c|c|}
\hline USPSTF$^{5}$ & $\begin{array}{c}\text { 40-49 } \\
\text { (Grade C: } \\
\text { Selectively } \\
\text { Recommend) } \\
\\
50 \\
\text { (Grade B: } \\
\text { Recommend) }\end{array}$ & $\begin{array}{c}2 \\
\text { (Grade B: } \\
\text { Recommend) }\end{array}$ & $\begin{array}{c}74 \\
\text { (Grade B: } \\
\text { Recommend) }\end{array}$ & $\begin{array}{c}\text { Grade } C \text { implies women } \\
\text { can choose the option to } \\
\text { initiate screening between } \\
\text { ages } 40-49 \text { years if they } \\
\text { value the potential benefits } \\
\text { of BCS mammography } \\
\text { greater than the potential } \\
\text { risks. }\end{array}$ \\
\hline
\end{tabular}

Adapted from:

1. American College of Obstetrics and Gynecologists (ACOG)

The American College of Obstetricians and Gynecologists. (2017). ACOG practice bulletin: Clinical management guidelines for obstetrician-gynecologists Retrieved from https://www.acog.org/Clinical-Guidance-and-

Publications/Practice-Bulletins/Committee-on-Practice-Bulletins-Gynecology/Breast-Cancer-Risk-Assessment-andScreening-in-Average-Risk-Women?IsMobileSet=false

\section{American College of Radiology (ACR)}

Lee, C. H., Dershaw, D. D., Kopans, D., Evans, P., Monsees, B., Monticciolo, D., ... Burhenne, L. W. (2010).

Breast cancer screening with imaging: Recommendations from the society of breast imaging and the ACR on the use of mammography, breast MRI, breast ultrasound, and other technologies for the detection of clinically occult breast cancer. Journal of the American College of Radiology, 7(1), 18-27. doi:10.1016/j.jacr.2009.09.022

Monticciolo, D. L., Newell, M. S., Hendrick, R. E., Helvie, M. A., Moy, L., Monsees, B., . . Sickles, E. A. (2017). Breast cancer screening for average-risk women: Recommendations from the ACR commission on breast imaging. Journal of the American College of Radiology, 14(9), 1137-1143. doi:10.1016/j.jacr.2017.06.001

\section{American Cancer Society (ACS)}

Oeffinger, K. C., Fontham, E. T. H., Etzioni, R., Herzig, A., Michaelson, J. S., Shih, Y. T., . . Wender, R. (2015).

Breast cancer screening for women at average risk: 2015 guideline update from the American cancer society. Jama, 314(15), 1599-1614. doi:10.1001/jama.2015.12783

\section{National Comprehensive Cancer Network (NCCN)}

Bevers, T. B., Helvie, M., Bonaccio, E., Calhoun, K. E., Daly, M. B., Farrar, W. B., . . Kumar, R. (2018). Breast cancer screening and diagnosis, version 3.2018, NCCN clinical practice guidelines in oncology. Journal of the National Comprehensive Cancer Network: JNCCN, 16(11), 1362-1389. doi:10.6004/jnccn.2018.0083

\section{United States Preventive Services Task Force (USPSTF)}

Siu, A. L. (2016). Screening for breast cancer: U.S. preventive services task force recommendation statement. Annals of Internal Medicine, 164(4), 279. doi:10.7326/M15-2886

\section{The United States Preventive Services Task Force (USPSTF) currently recommends}

biennial mammograms for females starting at age 50 and continuing until age 74 (Siu, 2016). For women ages 40 to 49 , the USPSTF recommends selective screening based on individual factors, given a lower net benefit of avoided breast cancer deaths versus harm (Nelson et al., 2016a; Sui, 2016). In this case, harm is defined as overdiagnosis and overtreatment. However, it is difficult to quantify if evaluation and treatment of the diagnosed breast cancer found on imaging would "become a threat to a woman's health, or even apparent, during her lifetime" (Siu, 2016, p.280, 
para 2). The USPSTF proposes these guidelines based using a meta-analysis using absolute rates that out of every 10,000 women aged 40-49 screened, there would be three fewer breast cancer deaths, in comparison to eight fewer deaths for women aged 50-59, and 21 fewer deaths in women aged 60-69 who had routine screening (Nelson et al., 2016a). This data implies younger women completing routine mammograms experience less breast cancer related deaths than older women, which would be expected since the incidence averages of breast cancer diagnosis and death in the United States are ages 62 and 68 (SEER, n.d.). The USPSTF's analysis of BCS effectiveness regards breast cancer mortality reduction as the primary positive outcome across all ages, as all-cause mortality was not found statistically significant, and the incidence of advanced breast cancer diagnosis based on screening was only found reduced for women ages 50 or older, but not for women ages 39-49 (Nelson et al., 2016a).

The USPSTF categorizes women who are considered average risk as those without personal or familial breast cancer history, without known BRCA1 or BRCA2 gene mutation, and without a history of radiation therapy to the chest at a young age (Sui, 2016). The USPSTF recognizes women with familial breast cancer history or possible genetic BRCA1 or BRCA 2 mutations at higher risk of developing breast cancer and may benefit from initiating screening earlier than 50 years (Nelson et al., 2016a; Sui, 2016). The USPSTF has a "B" recommendation for screening women for BRCA mutations and referral for genetic counseling should occur starting at age 18 and re-assessed "periodically" (Moyer, 2014, p. 274, para 2). However, no further recommendations addressing the frequency of BRCA mutation screening is offered. Screening recommendations for potentially high-risk women include those with familial members with "breast, ovarian, tubal, or peritoneal cancer," in addition to a positive screening result from one screening risk model (FHS-7, Manchester Scoring System, Ontario Family 
History Assessment, Pedigree Assessment Tool, Referral Screening Tool) (Moyer, 2014, p. 271, para 4). Females with risk factors or whom may experience significant familial medical history changes over time may miss opportunities of being identified for early detection screening without concrete recommendations.

In contrast, the National Comprehensive Cancer Network (NCCN) and American College of Radiology (ACR) recommend annual mammogram screening to start at age 40 with discontinuation dependent upon limited life expectancy (from factors such as co-morbidities, age) determined by provider discretion and if no further interventions (i.e. additional imaging, biopsies, breast cancer treatment) were to be pursued regardless of mammogram imaging results (Bevers et al., 2018; Lee et al., 2010; Monticciolo et al., 2017).

American College of Obstetrics and Gynecologists (ACOG) (2017) advises women should be counseled on BCS and be offered the choice to start mammograms at age 40 (but no later than age 50) determined through a shared-decision between the patient and provider. American Cancer Society (ACS) recommends annual screening mammogram starting at age 45 until age 54 (with individually tailored screening between the ages of 40-44), then every one to two years starting at age 55 onwards, until life expectancy is less than 10 years (Oeffinger et al., 2015).

The NCCN and ACR advocate for annual screening starting at age 40 because this age group has the largest potential to experience the benefits of breast cancer mortality reduction, improved survival rates, and better breast cancer treatment options (Bevers et al., 2018; Lee et al., 2010). Per the ACS (2017a), estimated breast cancer death rates for women ages 40-49 were $9 \%, 19 \%$ for women ages $50-59,23 \%$ for women ages $60-69,20 \%$ for women ages $70-79$, and the highest occurrence of $27 \%$ in women aged 80 and above. The ACS's recommendation to 
start mammograms at age 45 is based on quality evidence ratings found in their conducted systematic review evaluating the harms and benefits of BCS in 5-year intervals (Oeffinger et al., 2015). ACS advocates for introducing the discussion for BCS at age 40 to identify women at higher risk that would benefit from mammography earlier than age 45 (Oeffinger et al., 2015).

ACOG (2017) endorses counseling for BCS starting at age 40, with the option to start mammography because evidence from the ACS and USPSTF reviews found women receiving mammograms between ages 40-49 experience quantifiable breast cancer mortality reduction (Nelson et al., 2016a; Oeffinger et al., 2015). ACOG (2017) also supports a patient's decision to defer beginning mammograms until age 50, because determining an appropriate balance between harm versus benefit is subjective and should incorporate the patient's priorities and beliefs. Overall these guidelines propose patient involvement through a shared decision making approach, suggesting that BCS may not fit a standardized "one size fits all” approach.

There is general consensus amongst ACOG, ACR, ACS, and NCCN that women with average risk of developing breast cancer are those without personal or familial breast/ovarian cancer history, genetic predisposition for suspected or known gene mutations, or have a history of ionizing radiation exposure to the chest at a young age (10-30 years) (ACOG, 2017; ACS, 2017a; Bevers et al., 2018; Daly et al., 2017; Lee et al., 2010). Depending on the risk factor, women may benefit from earlier screening mammograms, additional imaging modalities, and genetic counseling. Identifying and following women who may not have initial risk factors, but develop them over time should be a part of a routine assessment, and re-evaluated regularly for best management of comprehensive BCS practices. Other breast cancer risk factors identified among these organizations include dense breast tissue, history of DCIS or LCIS, benign breast disorders, women of Ashkenazi Jewish decent, nulliparity or first pregnancy after age 35, early 
menarche (age 11 or younger), late menopause (after 55 years), never having breastfed, postmenopausal combination hormone therapy, and post-menopausal high bone mineral density (ACOG, 2017; ACS, 2017a; Lee et al., 2010). Environmental and behavioral influences contributing to breast cancer include alcohol consumption, tobacco smoking, obesity, diethylstilbestrol exposure, and working night shifts (ACOG, 2017; ACS, 2017a).

The lack of uniform BCS guidelines or a standardized decision toolkit for when to implement screening has caused inconsistent practices in primary care, potentially affecting outcomes for all women, including those at average or high risk. This difference in clinical practice ultimately impacts the opportunity to optimally screen and re-screen women for breast cancer in early detection, secondary, or tertiary care.

\section{Current Practice and Insurance Coverage}

Initiatives C-17 and C-18.1 from Healthy People 2020 aims for a 10\% improvement in the proportion of women ages 50-74 who receive BCS (target of $81.1 \%$ ), and are counseled by their providers about mammograms (target of 76.8\%) (Office of Disease Prevention and Health Promotion, 2018a). Data from the 2015 National Health Interview Survey indicates that only $71.6 \%$ of females aged 50-74 years in the United States receive BCS, and only $66.7 \%$ are counseled by their providers about screening mammograms (Office of Disease Prevention and Health Promotion, 2018a). The suboptimal screening rate shows a large percentage of the female population was not offered screening for early detection, which can be a life-saving preventative service. Conflict in recommendations among the ACOG, ACR, ACS, NCCN, and the USPSTF regarding screening women under the age of 50, suggests there is a greater gap of missed opportunities for providers to offer high-quality, comprehensive care to their patients. 
Radhakrishnan et al. (2017) conducted a national survey of primary care providers about their BCS practices, and found that physicians primarily trusted BCS recommendations from ACS, ACOG, and USPSTF. Each of these guidelines endorses different initial screening ages, ongoing screening frequency, and age at which to discontinue mammography. In this study, $81 \%$ of physicians reported offering BCS mammography to women aged 40-44, $88 \%$ to women aged 45-49, and 67\% offered mammography to women 75 or older (Radhakrishnan et al., 2017). These varying practices among providers represent the lack of a clear algorithm or screening process that incorporates all the best evidence-based recommendations to provide high quality care for optimal breast health. Furthermore, rescreening guideline practices fluctuate from annually to biennially between organizations and for the ACS, the frequency changes from one to two years after age 55. Radiology reports of the testing agencies performing the mammograms often follow the ACR guidelines, which offers recommendation for annual screening for women of all ages. In some cases, patients may be elicited back for routine annual follow-up by the testing agency, which may directly conflict with the chosen practice guidelines of the primary care institution. This implicates a potential for further confusion among primary care clinics selecting a standard institutional recommendation to follow, as well as lack of clarity for providers in navigating appropriate care for each female patient.

The current BCS practice that is most widely used, is the USPSTF guideline. The Centers for Medicare and Medicaid Services (CMS) utilize the recommendations to establish the standard protocol and evaluate core measures of quality health outcomes (Kaiser Family Foundation, 2018). To date, Medicare Part B completely covers annual mammography screening starting at 40, however, Medicaid BCS coverage is dependent on the Affordable Care Act (ACA) criteria for that state (Kaiser Family Foundation, 2018). Many private and individual insurance 
plans fall under the ACA provisions that utilize the USPSTF's grade "A or B" and Health Resources and Services Administration (HRSA) practice recommendations (Kaiser Family Foundation, 2018). The USPSTF grade "C" recommendation (stance originally published in 2009 and again in 2016) to selectively offer certain women to undergo mammography ages 4049, reflected in 2009 that not all health insurances were required to provide full insurance coverage consequently creating a barrier of accessibility to screen for women in this age range (Sui, 2016). In attempt to reduce this health disparity, in 2012 the Department of Health and Human Services (DHHS) implemented a provision requiring the ACA to use the 2002 USPSTF recommendations for BCS that entail a women can receive mammography starting at age 40 every one to two years with or without clinical breast exams (National Women's Law Center, 2013). This provision remains enacted due to the passing of the Comprehensive Omnibus Funding law in 2015 (Sui, 2016). HRSA (2018) also updated its recommendation guidelines in 2016 founded upon the Women's Preventive Services Initiative (organized by ACOG) and follow the same ACOG proposals. BCS is a preventative health service that should be offered to any women seeking this care. Lack of insurance coverage or potential costs associated should not interfere with universal preventative screens or prohibit a women's access to BCS services.

Epidemiology. Worldwide, breast cancer is the most common cancer in females for both the developed and underdeveloped countries (World Health Organization [WHO], 2018). With estimates of 508,000 deaths due to breast cancer in $2011,50 \%$ of cases and $42 \%$ of those deaths occurred in developed countries. In the North and South Americas, there is a $25.2 \%$ incidence of breast cancer in women of all ages and a $15.1 \%$ occurrence of death related to breast cancer (Global Cancer Observatory, 2018). By 2030, it is projected in the North and South Americas 
there will be an additional 572,000 new breast cancer cases and 130,000 deaths with the United States leading in breast cancer incidence (Global Cancer Observatory, 2018).

In 2015, the United States Cancer Statistics Working Group (2018) reported there were a total of 242,476 females diagnosed with breast cancer. Of those diagnosed (Table 2), Caucasian women experience the highest incidence of new breast cancer diagnosis, secondary to African Americans, followed by Asians, Hispanics, and Native American women. While this data captures the diagnosed rates, it is unclear whether the lack of screening contributes to these lower rates among the minority population. This data also captures the age-specific rates of new breast cancer diagnosis from 40-79 years (Table 3). This information reflects a clear escalation in the quantity of women diagnosed with breast cancer as one ages. It is noteworthy that women aged 75-79 experience the second highest rate of new breast cancer diagnosis, but it is an 'I' (insufficient) recommendation by the USPSTF due to the lack of high-level evidence (United States Preventative Services Task Force, 2019).

Table 2: 2018 Reported Number of females diagnosed with Breast Cancer

\begin{tabular}{|c|c|}
\hline Identified Race & $\begin{array}{c}\text { Number of Females } \\
\text { Diagnosed with } \\
\text { Breast Cancer per } \\
100,000\end{array}$ \\
\hline White & 125.6 \\
\hline Black & 123.3 \\
\hline Asian/Pacific Islander & 94.3 \\
\hline Hispanic & 93.6 \\
\hline American Indian/Alaskan Native & 71.2 \\
\hline
\end{tabular}

United States Cancer Statistics Working Group. (2018). United States cancer statistics: Data visualizations. Retrieved from https://gis.cdc.gov/Cancer/USCS/DataViz.html

Table 3: 2018 Reported Age Specific Rates of New Breast Cancer Diagnosis

\begin{tabular}{|c|c|}
\hline Age & $\begin{array}{c}\text { Number of Females } \\
\text { with New Breast } \\
\text { Cancer Diagnosis } \\
\text { per 100,000 }\end{array}$ \\
\hline
\end{tabular}




\begin{tabular}{|l|l|}
\hline $40-44$ & 126.2 \\
\hline $45-49$ & 190.1 \\
\hline $50-54$ & 224.8 \\
\hline $55-59$ & 262.6 \\
\hline $60-64$ & 334.4 \\
\hline $65-69$ & 421.2 \\
\hline $70-74$ & 461.9 \\
\hline $75-79$ & 445.5 \\
\hline
\end{tabular}

United States Cancer Statistics Working Group. (2018). United States cancer statistics: Data visualizations. Retrieved from https://gis.cdc.gov/Cancer/USCS/DataViz.html

California's leading cancer diagnosis is female breast cancer (NBCCEDP, 2013). At age 45-65, there is a 1:21 ratio for the probability of female breast cancer diagnosis in California, and 1:14 chance between ages 65-85 (American Cancer Society, 2013). Surveillance mammograms have been identified as an effective screening tool for identifying breast cancer and when done before an individual becomes symptomatic, early stage diagnosis and successful treatment with cure is higher. If breast cancer is found to be localized at the time of diagnosis, the five-year survival rate is $100 \%$ (American Cancer Society, 2013).

\section{Setting}

The Federally Qualified Health Center (FQHC) chosen for this doctoral project provides care to women that are American Indians, Alaskan Natives, Black, Asian, Hispanics, and NonHispanics of the surrounding Bay Area (Oakland, Alameda, Richmond, and San Francisco). The FQHC in Oakland primarily works with members that lack healthcare coverage, are underserved, and have low socioeconomic status. Disparity factors of educational level, income, occupation, and environmental exposures predispose and contribute to the risk of development of illness, disease, and breast cancer (Office of Disease Prevention and Health Promotion, 2018a). The opportunity to improve BCS coverage for all female members and possibly impact health outcomes compelled the author to collaborate and conduct the project at this clinical site. 
From September 2017 to 2018, the race of women at FQHC aged 50-74 years that were eligible for BCS (836 total) were identified (Table 4) as African American women as the highest secondary to Latino or Hispanic women, followed by American Indian/Alaskan Native, Caucasian, Asian, declined to specify/other/unknown, Native American, Native Hawaiian or Pacific Islander, and Middle Eastern or North African. Of this population, compliance rates in alignment with FQHC's current standards that utilizes the UPSPSTF's guidelines show Native Hawaiian or Other Pacific Islander women with the highest mammogram completions and Asian women with the lowest. Of the nine patient identified races, only Native Hawaiian or Other Pacific Islander women currently meet Healthy People 2020's C-17 objective target of an $81.1 \%$ rate of receiving BCS (Office of Disease Prevention and Health Promotion, 2018a). The varying rates of mammogram screening completions reflects an under performance in secondary preventative care despite FQHC's current system of screening. This reveals an opportunity for improvement and understanding of how certain races have higher rates of mammography completion and the barriers preventing those with lower percentages.

Table 4: Mammogram Screening Rates Based on FQHC's Current Breast Cancer Screening Guidelines (USPSTF: Biennial Screening for females ages 50-75)

\begin{tabular}{|l|c|c|c|}
\hline Patient Identified Race & $\begin{array}{c}\text { Eligible } \\
\text { (Total: 836) }\end{array}$ & $\begin{array}{c}\text { Did Not Receive } \\
\text { Mammogram (Total: 237) }\end{array}$ & $\begin{array}{c}\text { Compliance } \\
\text { Rate }\end{array}$ \\
\hline $\begin{array}{l}\text { Native Hawaiian or Other Pacific } \\
\text { Islander }\end{array}$ & 30 & 3 & $90 \%$ \\
\hline Latino or Hispanic & 213 & 46 & $78.4 \%$ \\
\hline $\begin{array}{l}\text { Declined to } \\
\text { specify/Other/Unknown }\end{array}$ & 39 & 9 & $76.9 \%$ \\
\hline Native American-Multi-Race & 38 & 10 & $73.6 \%$ \\
\hline Black or African American & 271 & 75 & $72.3 \%$ \\
\hline Middle Eastern or North African & 18 & 6 & $66.6 \%$ \\
\hline
\end{tabular}




\begin{tabular}{|l|c|c|c|}
\hline White & 80 & 29 & $63.7 \%$ \\
\hline American Indian/Alaskan Native & 85 & 32 & $62.3 \%$ \\
\hline Asian & 41 & 21 & $48.7 \%$ \\
\hline
\end{tabular}

I2I Tracking search conducted for 9/10/17-9/10/2018

In Alameda County, the 2014 reported annual percentage of female breast cancer cases diagnosed at an early stage (localized or in situ) are 76.9\% for Non-Hispanic White, $65.9 \%$ for African American, $70.4 \%$ for Hispanic, and $75.9 \%$ for Asian/Pacific Islander females respectively (ACS, 2017b). The actual rates in percent are not available for the following populations: American Indian and Alaskan Native females. However, the Office of Disease Prevention and Health Promotion (ODPHP) suggest that about 53.1\% of American Indians and Alaska Natives females are screened with mammograms (Office of Disease Prevention and Health Promotion, 2018c). This is $21.4 \%$ lower than the highest group of African American women receiving breast cancer mammography within the last two years (Office of Disease Prevention and Health Promotion, 2018c). Lower screening rates among this population reflect a higher risk for missed routine care and preventative health services. With less access to comprehensive care, these vulnerable populations will consequently suffer larger health disparities.

\section{Available Knowledge}

Given all the various guidelines, there remains confusion among providers, about which guideline is best and when to actually start screening. There is considerable debate about the risks of mammography screening causing 'harm' to women in their 40 s that could lead to increased false-positives requiring additional imaging, the risk of radiation induced breast cancer from the cumulation of mammography, the potential for overdiagnosis, and additional 
psychological stress (Nelson et al., 2016b). The PICOT questions asked to further understand the current evidence, gaps, and risks of age-based routine breast screening are as follows:

1) Do guidelines $(\mathrm{C})$ for starting $\mathrm{BCS}(\mathrm{O})$ in females $(\mathrm{P})$ vary by age $(\mathrm{T})$ for routine screening mammograms (I)?

2) Do the contrasting (C) screening guidelines (I) affect outcomes for breast cancer identification $(\mathrm{O})$ in females $(\mathrm{P})$ aged 40-49 (T)?

3) What are the advantages (O) and disadvantages (C) of starting screening early versus late (I), for women aged 40-49(P)?

4) What are the risk factors (I) predisposing women (P) towards developing breast cancer (O) earlier than the general population $(\mathrm{C})$ ?

A systematic literature search was conducted in October 2018 and again in March 2019 to effectively evaluate available evidence. The databases searched were CINAHL, Cochrane Database of Systematic Reviews, and PubMed. Keywords and MESH terms included mammography, age factors, adverse effects, benefits, risk factors, BRCA1/2 mutations, family history, chest radiation outcomes, breast neoplasms, breast cancer, and screening alone and in combinations. Gray area literature and search engines utilized were ACOG, ACR, ACS, CDC, NCCN, UpToDate, and USPSTF. Reference lists of preliminary research articles were scanned for articles that could be considered for further review. Inclusion criteria were: articles published between 2008-2019 for the most current data and existing practices recommended to the public and health care providers regarding BCS, and articles written only in the English language. A total of 136 articles were found, 21 were selected for further consideration based on the inclusion criteria, and 8 were included in this review. Articles excluded did not further clarify and answer the reviews aim in evaluating best practice management of BCS for women aged 40-49. Multiple 
studies that were reviewed included meta-analysis', systematic reviews,

prospective/retrospective studies, and practice guideline recommendations. The evidence was evaluated using the John Hopkins Research and Non-Research Evidence Appraisal Tools (2012a, 2012b) and rated for quality (Appendix C). The articles presented in this paper range from Level I A to III C.

\section{Review of Literature}

After thorough examination of the current evidence, the leading arguments of the potential risks and benefits of BCS practices are described to help educate the author and readers to make informed, comprehensive decisions about breast health. The themes of possible disadvantages towards screening women ages 40-49 are false-positive recalls from mammography, false-positive readings leading to biopsy, overdiagnosis of breast cancer leading to potential unnecessary treatment, psychological stress, and mammography related radiation risk. Beneficial themes of screening women ages 40-49 reviewed are earlier stage of breast cancer diagnosis, decreased breast cancer related mortality, increased number of lives saved from routine BCS, and the potential of years of life gained from earlier detection (Appendix C).

\section{Disadvantages to Breast Cancer Screening with Mammography (for women aged 40-49)}

False-Positives. The potential risk for women receiving a false-positive finding from a mammogram that is truly negative for breast cancer has been documented as a considerable factor that can influence the individual decisions towards BCS. Pace and Keating (2014), the USPSTF, and the ACS systematic reviews demonstrate a $61.3 \%(95 \% \mathrm{CI})$ risk of receiving at least one false-positive finding over 10-years for women who started annual screening at age 40, and $41.6 \%(95 \% \mathrm{CI})$ respectively for those continuing with biennial screening (Nelson et al., 2016b; Oeffinger et al., 2015). However, comparable estimates for false positives in women 
starting mammogram screening in their 50s were discovered at $61.3 \%$ (95\% CI) annually and 42\% biennially (Nelson et al., 2016b; Oeffinger et al., 2015; Pace \& Keating; 2014). This evidence shows women in their 40s will experience near identical estimates of false-positive recalls compared to those in their 50s regardless of the screening interval. The Van den Ende et al. (2017) systematic review examined the effects of BCS for only women aged 40-49 and found a $20.5 \%$ cumulative risk of experiencing a false-positive finding within the first seven mammograms. This finding suggests there is possibly lower rates of false-positives findings indicating some variability for women aged 40-49 than reported by the USPSTF, ACS, and Pace and Keating (2014) systematic reviews. The decision to choose whether this disadvantage outweighs to begin mammogram screening during age 40 or 50 should be the choice of the individual undergoing the intervention rather than the standardized guidelines produced by governing institutions.

Myers et al. (2015) found false-positive mammograms leading to biopsy recommendations for a first time screen increased with age (OR 1.40 aged 40-44, 1.75 for 50-54 years, and 1.75 for 55-59 years). Over the course of ten years, cumulative estimates of biopsy recommendation from false-positive mammograms exhibit a 7\% (95\% CI) increased risk during annual screening for women in their 40s versus a 9.4\% risk for women in their 50's (Myers et al., 2015; Nelson et al., 2016b; Oeffinger et al., 2015). During biennial screening, the risk for false positives for women in their 40's was $4.8 \%$ versus $6.4 \%$ for women in their 50 s (Myers et al., 2015; Nelson et al., 2016b; Oeffinger et al., 2015). These results show that women in their 50's carry a higher risk for false positives than women in their 40's regardless of annual or biennial screening. This suggests the need to avoid the risk for false-positive findings with follow-up recommendation for additional imaging or biopsy remains consistent at any age, and should not 
be a limiting factor with beginning screening at age 40 versus 50 . Factors that could contribute and affect false positive rates include breast density, type of imaging modality utilized, postmenopausal hormone therapy, timing of first mammogram, interval rescreen rate, and lack of comparison mammogram images (Nelson et al., 2016b; Oeffinger et al., 2015). Modifiable and non-modifiable risk factors are not discussed with this study and could impact these results.

Overdiagnosis. Overdiagnosis might be considered the greatest harm for a woman obtaining mammogram imaging. Overdiagnosis is defined as the diagnosis of "cancer with a screening test (such as a mammogram or PSA test) that will never cause any symptoms. These cancers may just stop growing or go away on their own" (National Cancer Institute, n.d.). The ACS, USPSTF, Myers et al. (2015), Pace and Keating (2014), and van den Ende et al. (2017) systematic reviews state overall predication estimates for breast cancer overdiagnosis range widely from $0-54 \%$ due to varying measures such as the BCS practices utilized, disease incidence with or without screening, inclusion or exclusion of ductal carcinoma in situ, and lead time adjustments (described as the time gained before cancer incidence from early detection) (Nelson et al., 2016b; Oeffinger et al., 2015). Furthermore, no one individual has the same underlying predisposing risk factors, behavioral influences, values, socioeconomic status, and access to resources. Due to the variability in estimating the impact of breast cancer overdiagnosis from mammograms, Myers et al. (2015) and Oeffinger et al. (2015) determined the quality of quantifiable data to be low. The ACS, USPSTF, Myers et al. (2015), Pace and Keating (2014), and van de Ende et al. (2017) share the understanding that it is difficult to quantify the impact of overdiagnosis because there lacks a clear consensus on the best approach of how to measure and evaluate this outcome (Nelson et al., 2016b; Oeffinger et al., 2015). Without demonstrating 
sound quality evidence in the rates of overdiagnosis related to BCS, it is difficult to synthesize this factor as an influence toward guideline recommendation and provider-to-patient counseling.

Psychological Impact. The USPSTF considers and accounts for the potential negative psychological impact, that mammography screening may have on women, as a 'harm' to BCS screening (Nelson et al., 2106b). USPSTF found that women who had negative mammogram results experienced less anxiety and distress than those with other outcomes (Nelson et al.,2016b). Mixed results were reported and not found significant among for women not returning to their next scheduled mammogram after experiencing a previous false-positive result (Nelson et al., 2016b). Pace and Keating (2014) suggest that women with false-positive findings experienced higher levels of situational distress but did not elicit the diagnosis of major depressive or anxiety disorder. Evaluating the extent of individualized concern caused by factors from potential negative outcomes of screening is a subjective finding that is balanced differently for each patient and difficult to translate across a general population.

Mammography Radiation Risk. There are currently no studies that directly measure the risk of cumulative mammography radiation induced breast cancer (Nelson et al., 2016b; van den Ende et al., 2017). Rather, the USPSTF reports modeling studies predicted women aged 40-59 years experienced 11 per 100,000 radiation induced breast cancer deaths and 2 per 100,000 for women aged 50-59 (Nelson et al., 2016b). ACOG (2017) states 125 of 100,000 women receiving annual mammography ages 40-74 were diagnosed with radiation induced breast cancer from mammograms that resulted in 16 deaths, but 968 breast cancer deaths were averted by screening. These estimates elude that the possibility of avoiding multiple breast cancer deaths by decreasing radiation exposure, may outweigh the potential risks of mammography to screen for cancer and save other lives. 


\section{Advantages of Screening (for women aged 40-49)}

Surveillance mammograms have been identified as an effective screening tool for identifying breast cancer and when done before an individual becomes symptomatic, early stage diagnosis and successful treatment with cure is higher. If breast cancer is found to be localized at the time of diagnosis, the five-year survival rate is $98.8 \%$ (SEER, 2018). Screening findings with advanced cancer stages, has a five-year survival rate of 27.4\% (SEER, 2018).

Earlier Diagnosis Stage. Mammograms conducted in women aged 40-49 offer the opportunity to begin provider-to-patient education sooner, diagnose breast cancer earlier, treat more successfully, and reduce overall mortality (Shen et al., 2011). A 10-year retrospective study comparing women aged 40-49 with mammography (145) and non-mammography (166) detected breast cancer exhibited smaller average tumor diameter size $(20.68 \mathrm{~mm}$ versus $30.38 \mathrm{~mm}$; $\mathrm{p}<0.0001)$, less sentinel lymph node involvement $(\mathrm{p}<0.0001)$, increased 5-year disease free rate (94\% versus $71 \%$ ) and better overall survival estimates (97\% versus 78\%) (Shen et al. 2011). This statistically significant data demonstrates that females in their 40s who are at average risk for developing breast cancer and receive mammograms earlier than the USPSTF's recommendations have better outcomes for earlier diagnosis, less reoccurrence or metastatic spread, and less mortality rates (Shen et al., 2011). Women ages 45-49 and 50-54 experience the same burden of disease (about 15\% of years of life lost per age bracket) (Oeffinger et al., 2015). Even with this knowledge, current practice guidelines conflict and differ amongst each other prohibiting a cohesive standardized decision making model.

Decreased Mortality. Reduced breast cancer mortality in women who begin screening with mammography in their 40s is evident across the majority of studies (Magnus et al., 2011; Myers et al., 2015; Nelson et al., 2016a; Oeffinger et al., 2015; Pace and Keating, 2014). Van 
den Ende et al. (2017) report in their systematic review of four articles reviewing two randomized controlled trials (the Age trial and the Canadian National Breast Screening Study-I (CNBSS-1)) that there was no statistically significant difference found in breast cancer mortality for women screened ages 40-49 years. However, van den Ende et al. (2017) identifies limitations in both studies where the quality of mammogram technology and radiology interpretation in the CNBSS-1 trial were possibly sub-standard, and in the Age Trial, after the initial mammogram, all subsequent screenings were completed as single view instead of the standard two view screening mammogram. Van den Ende et al. (2017) demonstrates the only non-significant finding concerning breast cancer mortality reduction with screening women routinely in their 40 s.

Magnus et al. (2011) meta-analysis found a 17\% mortality reduction for women who had screening mammograms between ages 39-49. Myers et al. (2015) and Pace and Keating (2014) systematic reviews found a $15 \%$ mortality reduction for women beginning screening less than 50 years. The ACS graded the outcome of reduced breast cancer mortality evidence in women younger than 50 as high (Oeffinger et al., 2015). The 5-year absolute risk of women developing breast cancer at 5-year intervals is: $0.6 \%$ during ages $40-44,0.9 \%$ during ages $45-49$, and $1.1 \%$ during ages 50-54 (Oeffinger et al., 2015). Mortality reduction is clearly evident in women receiving mammograms earlier than 50 .

Lives Saved/Potential Years of Life Gained. It is undeniable that mammography is the best available diagnostic imaging modality and gold standard for detecting breast cancer (World Health Organization, 2018). Pace and Keating (2014) found in their systematic review that 5 out of every 10,000 women aged 40-49 years, 10 out of every 10,000 women aged 50-59 years, 42 out of every 10,000 women aged 60-69 years will be saved from mammograms. The USPSTF 
found biennial mammography for women aged 40-74 gained 152 lifetime years and avoided eight breast cancer deaths per 1,000 versus women aged 50-74 gained 122 total years of life and avoided seven breast cancer deaths (Sui, 2016). The ACR estimates based on their recommended screening strategy, women receiving annual screening ages 40-84 per 1,000, experienced 11.9 BC deaths prevented, and 189 years of life gained (Monticciolo et al., 2017). ACR estimates using the USPSTF's recommendation for biennial mammography from ages 50-74 that 6.95 BC deaths are prevented, and 110 years of life are gained (Monticciolo et al., 2017). Evidence suggests those screened earlier and more frequently have the potential to experience lengthier lives and fewer deaths.

\section{Rationale}

Theoretical/Conceptual Frameworks. The theoretical framework that will guide this project is Jean Watson's Philosophy and Science of Caring that encompasses the concepts of human being, health, environment, and nursing (Petiprin, 2016). Watson identifies the human being as a unique individual that requires the time, patience, and respect to be understood and valued. She defines health as the physical and mental levels of well-being with efforts towards the absence of disease. The environment focuses on health care professionals and their exposure to socio-cultural experiences that provides opportunity to interact, reflect, and grow. Cultivating personal and professional self-awareness allows for the provider to be present, non-judgmental, and engaging in a caring manner with the patient. Watson's model is parallel to the nursing process in creating and establishing a comprehensive care plan that is holistic in nature.

Watson's framework is grounded in approaching all human interactions in a caring inquiry to promote health while valuing patient autonomy (Petiprin, 2016). These fundamental concepts are what will structure the approach towards communicating and understanding 
perceived patient perceptions and values. BCS addresses health as a collaborative process between provider and patient, encouraging establishment of a comprehensive care plan, and ultimately optimizing breast health outcomes for each individual patient, instead of categorizing patients into groups, costing lives.

The Tannahill Model of Health Promotion is the formative theory that will represent this project's approach towards identifying and addressing breast health among women. This model aims at health promotion by incorporating community-based education through dissemination of best available evidence, protection through policy implementation, and prevention or early detection of disease through modern medicine (Tannahfill, 2009). This model will demonstrate health promotion of female breast health through analyzation of current literature, sharing this information to the health care team at $\mathrm{FQHC}$, and implementing an easy-to-use standard of practice toolkit to open a pathway for discussing and offering secondary screening measures for breast cancer.

The "appropriateness in patient care" is the conceptual framework that will be the foundation in creating an algorithm for the Screening Mammogram Initiation Protocol (SMIP) at FQHC. This will also help formulate the approach and process of how providers are to lead consultation with their patients regarding breast health. Sharpe \& Faden (1996) proposes "appropriateness" is characterized by valuing three point of views of the clinician, the patient, and the society. This framework emphasizes clinical recommendation by the health care provider are to be based on counseling best available literature. Discussion of all the available options and their potential outcomes with consideration of the patients' values and preferences are integral components of valuing "appropriateness" (Sharpe \& Faden, 1996). This concept in patient care highlights the significance of informed consent that is based on evidence, is non-biased, and a 
process of shared decision making between the patient and the provider. As critical as it is for a clinician to disseminate information on recommended medical interventions while weighing the health benefits versus risk for each patient, if the proposed intervention does not align with the patient's principles, then it is considered inappropriate to implement at that visit.

While treating the whole person in a holistic manner, it is essential to integrate scientific knowledge to ensure optimal patient outcomes. Evidenced based practice theory is the fundamental guide for the purpose of this Doctorate of Nursing Practice (DNP) project and efforts toward a practice change at FQHC. This theory promotes the dissemination of high-level research based on a hierarchal ladder into clinical practice. Translating evidence into the health care delivery system improves medical care and is vital towards meeting public health needs (Institute of Medicine, 2001). However, while evidence can be generalized in the efforts of a high-level study, sometimes evidence based practice theory can be contradictory in practice as the population is not generalized and may require more individualized approaches. Each patient is an individual with different values that are uniquely influenced by their social, environmental, spiritual, cultural beliefs, and experiences. This is a reminder that a harmonious balance between medicinal science and patient intervention is a collaborative process which urges an informed decision, requiring clinician dissemination of information and patient-centered decision making.

\section{Specific Aims}

By February 2019, primary care providers at the FQHC will receive an educational module on BCS guidelines, understand the importance of the evidence behind the current guidelines, and apprehend techniques for individualized approaches to screening mammograms using the Screening Mammogram Initiation Protocol (SMIP), developed by the author as a tool for aiding decision making for best screening initiation timeframe and cancer risk assessments 
(Appendix K). The providers will be able to participate in shared decision making, using an evidence based standardized approach. Screening may start early for some women, compared to the current approach of starting all women at age 50. Appropriate recommendation of care will be coordinated by achieving each of these objectives with the SMIP:

- Evaluate current best evidence and create an algorithm for breast cancer mammogram screening appropriate to risk and age for each female

- Assess and evaluate best approaches for successful implementation of algorithm

- Present educational session and implement SMIP into practice

- Improve provider knowledge and counseling/recommendation for mammogram with female members

\section{Section III: Methods}

\section{Context}

The SMIP protocol will be implemented using an educational and integrative approach. Education regarding BCS, discussion about guidelines, a review of current practice and risks, along with implementation of this algorithm in the clinic work flow to achieve full implementation of this protocol will be applied.

\section{Stakeholders}

Key stakeholders that will be directly involved with this project proposal include the DNP student, DNP chair, site leader, general practitioners, clinic management, and clinic staff. Recipients that will be affected by this intervention include female patients and their families of FQHC, their insurances/government, diagnostic testing centers, and specialty oncology clinics.

\section{Interventions}


After reviewing the current BCS guidelines and risk factors, the SMIP will be created by the DNP student. The SMIP is an evidence-based strategy designed as an algorithm for healthcare providers to educate and navigate women about their breast health throughout their life trajectory. This screening provision is an opportunity for professional development among healthcare professionals, a public outreach initiative to promote screening on disparate populations, and improvement on quality and assurance of reproductive services provided (National Breast and Cervical Cancer Early Detection Program [NBCCEDP], 2013). After collaborating with the DNP chair and site leader for the SMIP approval, the DNP student will meet with the FQHC director for project proposal and approval to implement the project. Education of providers will occur during one of their monthly, morning provider training meetings. A 10-minute PowerPoint presentation will be provided as an in-service to FQHC staff with handouts of the SMIP. Pre-surveys from the providers will also be collected.

The SMIP will be initiated the following week for 9-weeks for data collection. Currently, identified from I2I Tracking the medical assistants highlight female patients age 50-74 that are due for their biennial mammogram and are listed for clinical visits the following day. During their visit, either the medical assistant will ask if the patient needs a mammogram referral request and if they have further questions a discussion with the provider can occur. With the SMIP, identifying patients the day before will be eliminated. Instead, during the rooming process the medical assistants will review with female members ages 40 and 45, their risk factors for breast cancer (that can include the Gail Model assessment), then record and report findings to the treating provider. From those responses, the provider will be able to guide the discussion about the patient's individualized breast cancer risks and help the patient make an informed decision about mammography screening. From the providers documentation, the patient's preference on 
the interval for mammograms will be viewable for future management in secondary screening care. Post surveys will be collected by the DNP student completed by the providers at the end of the project implementation. Analyzation of all data collected from pre/post surveys and I2I Tracking will be completed by the DNP student with assistance from Dr. Sandhu.

By integrating the SMIP into FQHC's practice, the project will offer overall greater awareness towards screening services for all female members, an EHR system with I2I Tracking that aligns and supports provider practice changes, a reduction in barriers and increased access to BCS (NBCCEDP, 2013). Increased and appropriate BCS, re-screening, and surveillance will impact health outcomes by reducing breast cancer morbidity and mortality, and reduce health disparities.

\section{Gap analysis}

The current standards of practice for mammogram screening at the FQHC follow the USPSTF guidelines. The USPSTF recommends biennial mammograms for women 50 and over who are at average risk until age 74 (Siu, 2016). A Family Nurse Practitioner at the FQHC initially shared concern over when to start the conversation with patient's about BCS, when to order mammography, and when to schedule follow-up imaging. He and other providers at the FQHC shared despite the governing USPSTF guidelines that initiate mammogram screening at age 50, there is no screening for any additional risks, or educating women about the possibility of starting earlier or at more frequent intervals. Mammograms are then continued biennially as per the recommendations of the USPSTF. Furthermore, considering females with breast cancer risk factors, there is no standard at FQHC guiding provider practices among earlier initial screening age, frequency, discontinuation, as well as mammogram test result recommendations for next routine follow-up. 
The lead Nurse Practitioner for this project was interviewed for a detailed gap analysis (Appendix D and E). The NP site leader expressed BCS and follow-up varies not only among providers, but also among different organizations, citing that every unremarkable radiology imaging report recommends to schedule the next mammogram in one year. This recommendation directly conflicts with the USPSTF's guidelines to image every 2-years for an average risk patient. From his interactions, other providers have expressed similar opinions and a general consensus of confusion with when to start, rescreen, and discontinue mammogram practices with their female population.

At the FQHC, I2I Tracking is a repository system that extracts electronic health record data from NextGen for the institution to understand areas of high performance and needs for improvement to support quality health outcomes, efficiency, and financial responsibility. Utilization of I2I Tracking found between the 12 months of September 2017-2018, 838 females ages 50-74 (parameters determined based on the FQHC's current standards of care adopted by the USPSTF guidelines) were eligible for breast cancer mammograms. Out of those 838 females, 599 were referred by clinicians and received mammograms showing a near $72 \%$ compliance. When age parameters were expanded from ages 40-74 (based on the ACOG, NCCN, and ACR's initial start age), 1322 females at the FQHC were eligible and 837 females were referred and received mammograms reflecting a $63.7 \%$ rate of mammography screening. This data suggests that provider practices are inconsistent with current FQHC standards for BCS mammography, and/or risk factors are not cohesively identified to implicate initiating earlier mammogram referral.

\section{GANTT}


This DNP project will take place from October 2018-April 2019. A GANTT chart illustrates the proposed project's timeline (Appendix F). Each task is reflected with which month each of these milestones are planned to be completed. These tasks follow the nursing process by first identifying the needs of FQHC's clinic through assessing the work environment and then determining a project idea. Planning will occur through a literature review and creating a practice based screening tool (SMIP). Implementation is conducted with an educational presentation with subsequent utilization in clinical practice for nine-weeks. This will simultaneously follow an evaluation with data collection and analysis. Lastly, the DNP student will complete the project summary and write-up to further disseminate the overall findings.

\section{Work Breakdown Structure}

The primary responsibility of the development, planning, implementation, and evaluation of this project is the DNP student (Appendix G). The DNP student will facilitate, coordinate, and lead this project with the support of the DNP chair, Dr. Sandhu and the clinical site mentor. The DNP student will work with Dr. Sandhu to develop the Screening Mammogram Initiation Protocol (SMIP). The DNP student will provide an educational PowerPoint in-service, and help implement the SMIP. The Site Leader will extract the data collected on I2I Tracking for analysis. Health Care Providers and Medical Assistants will utilize the SMIP into clinical practice over a nine-week period. The DNP student will be able to utilize information collected from I2I Tracking and surveys to evaluate the projects efficacy and success.

\section{SWOT Analysis}

An analysis of the strengths, weaknesses, threats, and opportunities to the project have been performed to identify foreseeable issues with proposed solutions to support the success of this project (Appendix $\mathrm{H})$. 
Strengths. The FQHC's health care providers have expressed a need to better address and counsel patients on BCS and referral for mammograms. Integrating a standardized process will help maintain accountability to aid in prompting providers when their patients are due for mammogram screening discussion. Easy access of the algorithm with printed laminated handouts will help appropriately guide the screening process to improve identification of women eligible for mammography and are to receive counseling. This project has the opportunity to increase provider knowledge, enhance patient involvement, and provide both patient and provider empowerment in making decisions. Subsequently, this will foster collaborative discussions with members to promote patient centered care. Ultimately this can increase patient satisfaction scores and improve continuity of screening services, early detection, and referral for treatment in primary care.

Weaknesses. Potential issues that exist and challenge this project's success include a lack of a currently existing algorithm, differing views and/or limited time from providers, a lack of opportunity within the timeframe of the intervention, and possible lack of participation from the patients, given the time constraints and needs for enhanced education. A change in any protocol can be confusing for patients and take time to adopt. Development of an algorithm that has never been tested requires dedication and time to research and formulate. Utilization in a confined period can hinder the potential of a larger sample size for analysis. Health care providers may not prioritize BCS discussion in comparison to other acute health issues. Providers may also not have sufficient time between visits to optimally discuss breast health due to the lack of resources. Beliefs and values of the patient based on culture and/or religion can affect patient opinions of obtaining mammograms. Modern medicinal practices can be considered an invasive intervention 
in comparison to complementary alternatives such as the connectedness of spiritual healing and consciousness of balance between all elements that is practiced in Native American culture.

Opportunities. A culture shift is occurring towards emphasis on preventative health and screening in primary care. Many opportunities exist to improve the quality of care at FQHC. Including BCS discussions as part of the routine well women annual exam will raise awareness and promote holistic care. The Centers for Medicare and Medicaid created an electronic clinical quality measure, CMS125v6 to monitor the 2018 performance of women ages 50-74 obtaining mammograms to screen for breast cancer (Electronic Clinical Quality Improvement Resource Center, 2018). Starting screening early in some females and ensuring that screening will happen by age 50 for all females, will help the FQHC meet the goals of quality healthcare. The use of a standardized protocol will create a flow for early conversation and hopefully mitigate further delays in achieve successful screening mammogram rates. Production of this measure highlights the importance of monitoring screening rates in primary clinical care. The United States Department of Health and Human Services Health Resources and Services Administration (n.d.) further developed a detailed overview of the BCS quality measure to emphasize the importance of addressing high quality assurance in healthcare to improve outcomes.

Effective screening will improve Healthy People's 2020 target goals towards reducing health disparity rates of cancer related "illness, disability, and death" (Office of Disease Prevention and Health Promotion, 2018a). The National Committee for Quality Assurance (2018) Healthcare Effectiveness Data and Information Set shows the 2017 BCS rates based off of insurance coverage within the last two years among women ages $50-74$ were $72.7 \%$ for commercial Health Maintenance Organization (HMO) insurance, 70.2\% commercial Preferred Provider Organization (PPO) coverage, 58.3\% HMO Medicaid, 72.5\% HMO Medicare, and 
72.2\% PPO Medicare. This clinical performance shows up to a $13.9 \%$ range in variability of screening rates, suggesting the type of care coverage an individual has contributes towards the quality of comprehensive health sought and delivered. In 2016, "only $22 \%$ of uninsured women aged 40-64 received a mammogram in the past year, compared to 54\% of insured women" (American Cancer Society Cancer Action Network, 2016, para. 2). Furthermore, females not getting screening included $30 \%$ not insured, $62 \%$ uninsured, $25 \%$ college graduates, and $47 \%$ with less than 12 years of education further potentiating socioeconomic disparities (American Cancer Society Cancer Action Network, 2016).

Threats. Foreseeable threats that challenge the success of this project are the varying institutional and government agency guidelines on BCS, cultural/language barriers, and misinterpretations or errors of the algorithm. Adapting reputable guidelines onto one document will reflect the best attempt at integrating, while respecting all current screening recommendations but will not have proven generalizability. However, this will promote patientcentered care and decision making that will be established with the provider.

\section{Budget}

This project will not require significant financial cost, rather a commitment of time from the stakeholders and those directly affected by the intervention (Appendix I). Cost of supplies for the educational presentation is projected to be about $\$ 110$ and the student developing, implementing, and evaluating this project will not be financially compensated. The presentation will be conducted during the FQHC's monthly required provider in-service training meetings. Implementation of the SMIP will occur during a patient's well-women annual visit and will be of no extra cost. Due to the Affordable Care Act, women are no longer discriminated by health 
insurance coverage and have access to preventative care without cost-sharing (National Women's Law Center, 2013).

The economic burden of cancer in the United States in 2010 were estimated to be $\$ 124.5$ billion, $\$ 16.5$ billion towards female breast cancer as the highest cancer cost (Yabroff et al., 2011). In the United States an average cost of a mammogram for an uninsured individual is \$102, with Oakland, CA \$130 respectively (Cost Helper, 2018b and New Choice Health, 2019). However, all new health insurance companies after the Affordable Care Act was initiated in 2012 are required to cover mammograms every one to two years for women over 40 years without cost-sharing or co-payments (National Women's Law Center, 2013). Breast cancer treatment varies by stage and can involve surgery (i.e. lumpectomy or mastectomy), chemotherapy and/or biotherapy, radiation, and other ancillary treatments for symptom management, adverse or side effects, and unanticipated hospitalizations.

Insured patients receiving breast cancer treatment can easily reach their yearly out-ofpocket maximum from labs, copays for prescription drugs, physician visits, and individual drugs or treatments not covered by their insurance plan (Cost Helper, 2018a). For patients without insurance, surgery costs range from $\$ 15,000-\$ 50,000$, chemotherapy $\$ 10,000-\$ 100,000$ (or $\$ 7,000-\$ 40,000$ per treatment), with a total costs of treatment averaging $\$ 100,000$ to $\$ 300,000$ for advanced cases (Cost Helper, 2018a). For an average risk women ages 45-65, there is a 1:21 chance for developing breast cancer (ACS, 2013). For every 21 mammograms for uninsured females it will cost $\$ 2142$, less than any single treatment modality for diagnosed breast cancer that typically is comprised as multi-regimen.

\section{Communication Matrix}


Integrating each organization's recommendation into an easily comprehensible and usable toolkit will require current evidence-based research and planning (Appendix J). Project research, development, coordinating, and facilitation of this project will be the primary responsibility of the DNP student. Continual communication with the DNP chair and site leader will be conducted as appropriate to the project needs via in-person, email, and phone.

\section{Outcome Measures}

Based on current best evidence, the DNP student with guidance from the DNP chair, will create the SMIP intervention to standardize mammogram screening and referral in primary care. This intervention will help reduce missed screening opportunities due to a standardized protocol that integrates current evidence with EHR prompt reminders. This proposed intervention will improve health care provider knowledge and confidence to educate and offer appropriate referral. Outcome measures for this project's intervention will reflect the following:

- At least $80 \%$ of providers will increase their knowledge of when and how to counsel female members about breast health.

- At least 25 patients will receive counseling/recommendation for mammogram using the SMIP starting at age 40.

- At least $50 \%$ of the providers will acknowledge satisfaction with utilizing the SMIP algorithm for BCS.

\section{Analysis}

Qualitative data will be collected through pre and post educational and implementation surveys completed by health care providers at the FQHC. This data will reflect on the quality of the education provided, the feasibility using the SMIP algorithm, and open feedback from providers implementing the intervention. Quantitative data will be comprised of general and 
anonymous information collected from the electronic I2I Tracking. Data for analysis will include the number of females starting BCS at age 40 and 50, and the number of females eligible and referred for a mammogram. Quantitative information from the electronic I2I Tracking will be extracted into Excel spreadsheet software for analysis and evaluation. Planned data analysis will include the change in percent of knowledge, the change in percent of patients referred for mammogram, and the percentage rates of satisfaction using the Likert scale.

\section{Ethical Considerations}

This project focuses on quality improvement using evidence-based change in clinical practice (Appendix A). This project examines BCS practices before and after the project's intervention to female members at the FQHC that are primarily high-risk and have less access to resources. Competing reputable organizations recommend differing BCS practices that are notably earlier than the FQHC's current standards of practice that follow the USPSTF Guidelines. Health promotion is an on-going and applicable beneficent goal for every patient. Health care providers are responsible for educating patients and caregivers by providing comprehensive information to facilitate their right to make decisions (American Nurses Association, 2015). Health care providers are also responsible for utilizing evidence-based medicine in practice where appropriate. Determining appropriateness of screening should not be the sole responsibility of the provider, when guidelines that vary exist. Despite cultural/religious preferences, language barriers, or personal biases, it is a provider's “authority, accountability, and responsibility [to] take action consistent with the obligation to promote health and provide optimal care" (American Nurses Association, p. 7, 2015). Counseling on all opportunities to screen should be based on the values of patient benefits versus harm and is a collaborate and autonomous discussion between patient and provider. This project is a non-research project 
which will evaluate a quality improvement method, and does not require IRB approval (Appendix A).

\section{Section IV: Results}

\section{Results}

A total of 25 staff members (nurses, behavioral health, social work, advanced practice providers, physicians, and CEO) participated in the BCS educational presentation. Eleven providers participated in the pre/post knowledge surveys and nine completed the nine-week postimplementation evaluation (Appendix N). I2I Tracking recorded the number of eligible female participants for BCS and the number referred by providers based on the age ranges of 40-49 and 50-59 between February $6^{\text {th }}$ - April $10^{\text {th }}, 2019$ (Appendix O).

Pre/Post Knowledge Surveys. The pre knowledge survey was administered prior to the start of the educational, in-person presentation with the post knowledge survey provided after presentation completion (Appendix L). Questions one and two asked providers how well they understood the current BCS protocol at the FQHC of average and high-risk female patients with available options as 'less than I would like', 'about right', and 'more than I would like' (Appendix N). Results reflected a 19\% and 36.5\% improvement after the post-educational session. Question three evaluated how versed providers felt in regard to other various screening guidelines (ACOG, ACR, ACS, NCCN, USTPSTF) with selections to answer from 'not at all well informed,' 'somewhat well informed,' and 'very well informed.' The post knowledge survey showed a $26.5 \%$ increase where providers felt they were 'very well informed.' Question four supported a near unanimous response that providers felt it was 'very important' that patients receive counsel about mammogram screening guidelines to make individualized screening goals based on risk assessment. Only one response in the post knowledge survey chose it was 
'somewhat' important to provide shared-decision making BCS. Ninety percent answered (previously 82\%) that at this time they were 'very likely' to implement an individualized screening protocol based on risk factors. One answered in the post knowledge survey they would 'somewhat likely' utilize the SMIP. Free response feedback of "great work, I feel well informed after your lecture" and "thanks $;:$ " were written in the post-education.

Post Implementation Survey. The post implementation survey was provided by the clinical site mentor at the subsequent FQHC staff meeting on April 10 ${ }^{\text {th }}, 2019$ (Appendix L). Eighty-nine percent felt 'very comfortable' using the SMIP after nine-weeks and $11 \%$ felt 'somewhat comfortable' (Appendix N). In question two, $89 \%$ answered that it was 'very feasible' to incorporate the project into a women's annual exam and 11\% 'somewhat feasible.' Fifty-five percent of providers responded 'yes,' that they were more engaged in making BCS decisions with their patients using the SMIP, 33\% 'somewhat,' and 11\% 'not at all.' As a provider, $89 \%$ replied 'yes' that they saw value in initiating the SMIP protocol, $11 \%$ 'somewhat,' and 0\% 'not at all.' Open feedback responses were "Not sure if I'm really using this protocol, I use the USPSTF recommendations," "I love laminated patient education tools!," “great job! Go dons!," and "great work! Great protocol."

I2I Tracking Results. The electronic I2I Tracking system found after nine-weeks from the start of implementation that out of 842 women aged 40-49 that were eligible for BCS, 609 received referrals from their providers (Table $5 \&$ Appendix O). Seventy two percent were screened during the implementation phase in comparison to $64 \%$ pre-project. For women aged 50-59, 555 were eligible for BCS, 445 were referred from their providers, and $80 \%$ were screened (previously $73 \%$ ).

\section{Table 5:}




\begin{tabular}{|l|l|l|}
\hline Age & $\begin{array}{l}\text { Percent Screened Pre Project } \\
9 / 10 / 17-9 / 10 / 18\end{array}$ & $\begin{array}{l}\text { Percent Screened Post Project Implementation } \\
2 / 6 / 19-4 / 10 / 19\end{array}$ \\
\hline $40-49$ & $64 \%$ & $72 \%$ \\
\hline $50-59$ & $73 \%$ & $80 \%$ \\
\hline
\end{tabular}

(I2I Tracking search)

\section{Section V: Discussion}

\section{Summary}

Although there were minimal unfavorable responses in the pre/post knowledge and postimplementation surveys, overall feedback was positive and exceeded all desired project outcomes. Providers responded that they better understood the various BCS guidelines and the FQHC's BCS protocol for not only average risk, but also high-risk female patients. Providers weighed near unanimous importance in counseling women about their breast health and choosing when to start mammography based on individual risk factors. Nearly $90 \%$ of providers acknowledged satisfaction using the SMIP and during the nine-week implementation, 609 female patients ages 40-49 received provider referral for mammography.

\section{Interpretation}

For women under age 50, an $8 \%$ increase in the number of women who were referred for mammograms was observed. Based on these I2I Tracking results, however only an assumption can be made that the SMIP protocol was followed, since no direct patient or provider data was analyzed. For women aged 50-59, a 7\% increase in mammogram recommendation referrals were completed by providers, improving FQHC's BCS practice protocol, Health People 2020's initiatives $\mathrm{C} 17$ and 18.1, and meeting all various screening recommendations (regardless if it is the latest start age for their respective guidelines). It can be inferred that this project's educational session and non-validated SMIP tool improved provider knowledge and understanding of BCS and supported comprehensive counseling for women to make informed 
decisions about their breast health. It can be inferred that toolkits identifying women at risk for breast cancer or place higher value in the benefits of mammography over the 'harms,' are necessary in primary care to support the opportunity for earlier screening and potential diagnosis. It can be concluded that at this time there is no clear consensus on BCS recommendations, but rather it should be the choice of the patient after non-biased counsel by their respective provider. Instead of examining the number of completed mammograms, reimbursement measures should rather measure the number of women who received counseling on BCS.

\section{Limitations}

Unavoidable limitations without breaking HIPAA and requiring the assistance from the informational technologist to build tracking features in the EHR were if patients completed their mammogram after a referral was made, and if patients who received comprehensive BCS counsel by their respective provider chose not to have a mammogram at that time. Future studies examining the barriers for women to complete their screening mammogram and factors weighing the decision for or declining to start mammography are suggested to better improve the SMIP and overall BCS. A confounding variable that could have influenced the outcomes of this project was the need for the clinic to meet the 2018 Healthcare Effectiveness Data and Information Set (HEDIS) measures. HEDIS tracks and supports funding for FQHC with one measure directly examining BCS rates for women aged 50-74 years. The drive for the clinic to meet these requirements could have indirectly contributed to the increased rates of referral for women ages 50-59, but overall is supportive of improved breast health outcomes.

\section{Conclusions}

In light of advancing technology and the shift towards precision health, primary healthcare providers have the opportunity to initiate the discussion and counsel women on the 
risks, benefits, and limitations of BCS while incorporating patient values and preferences. There is an opportunity to promote BCS in various populations and decrease health disparities using primary care practice tools such as the SMIP. National goals to increase BCS interventions can be met and positively influence quality health care outcomes, screening efficiency, delivery of care, financial performance, and patient-provider satisfaction. Shared-decision making between provider and patient coupled with standard breast screening guidelines can ultimately empower women about breast health and improve patient outcomes.

\section{Section VI: Other Information}

\section{Funding}

This doctoral project received no sources of funding from any organization in the design, implementation, interpretation, and reporting of this work. 


\section{Section VII: References}

\section{References}

American Cancer Society Cancer Action Network. (2016). The Affordable Care Act: Improving access to breast cancer screening. Retrieved from https://www.fightcancer.org/sites/ default/files/ACA\%20Improving\%20Access\%20to\%20Breast\%20Cancer\%20Screenings \%2001.22.16\%20FINAL.pdf

American Cancer Society. (2017a). Breast cancer facts \& figures 2017-2018. Retrieved from https://www.cancer.org/content/dam/cancer-org/research/cancer-facts-andstatistics/breast-cancer-facts-and-figures/breast-cancer-facts-and-figures-2017-2018.pdf

American Cancer Society. (2017b). California cancer facts and figures 2017. Retrieved from https://www.cdph.ca.gov/Programs/CCDPHP/DCDIC/CDSRB/CDPH\%20Document\%2 OLibrary/CDOC/CA_CancerFactsAndFigures_Revised_June2017.pdf

American Cancer Society. (2019). How common is breast cancer? Retrieved from https://www.cancer.org/cancer/breast-cancer/about/how-common-is-breast-cancer.html

The American College of Obstetricians and Gynecologists. (2017). ACOG practice bulletin: Clinical management guidelines for obstetrician-gynecologists Retrieved from https://www.acog.org/Clinical-Guidance-and-Publications/Practice-Bulletins/Committeeon-Practice-Bulletins-Gynecology/Breast-Cancer-Risk-Assessment-and-Screening-inAverage-Risk-Women?IsMobileSet=false

Breastcancer.org. (2019). U.S. breast cancer statistics. Retrieved from https://www.breastcancer.org/symptoms/understand_bc/statistics

Bevers, T. B., Helvie, M., Bonaccio, E., Calhoun, K. E., Daly, M. B., Farrar, W. B., ... Kumar, 
R. (2018). Breast cancer screening and diagnosis, version 3.2018, NCCN clinical practice guidelines in oncology. Journal of the National Comprehensive Cancer Network : JNCCN, 16(11), 1362-1389. doi:10.6004/jnccn.2018.0083

Centers for Disease Control and Prevention. (2018). Breast cancer awareness. Retrieved from https://www.cdc.gov/cancer/dcpc/resources/features/breastcancerawareness/

Cost Helper. (2018a). Breast cancer treatment cost. Retrieved from https://health.costhelper.com/breast-cancer.html

Cost Helper. (2018b). Mammogram cost. Retrieved from https://health.costhelper.com/mammogram.html

Daly, M. B., Pilarski, R., Berry, M., Buys, S. S., Farmer, M., Friedman, S., . . Darlow, S. (2017). NCCN guidelines insights: Genetic/familial high-risk assessment: Breast and ovarian, version 2.2017. Journal of the National Comprehensive Cancer Network : JNCCN, 15(1), 9-20. doi:10.6004/jnccn.2017.0003

Electronic Clinical Quality Improvement Resource Center. (2018). Breast cancer screening. Retrieved from https://ecqi.healthit.gov/ecqm/measures/cms125v6

Health Resources and Services Administration. (2018). Women's preventive services guidelines. Retrieved from https://www.hrsa.gov/womens-guidelines/index.html

Kaiser Family Foundation. (2018). Coverage of breast cancer screening and prevention services. Retrieved from https://www.kff.org/womens-health-policy/fact-sheet/coverage-of-breastcancer-screening-and-prevention-services/

Lee, C. H., Dershaw, D. D., Kopans, D., Evans, P., Monsees, B., Monticciolo, D., ... Burhenne, L. W. (2010). Breast cancer screening with imaging: Recommendations from the society of breast imaging and the ACR on the use of mammography, breast MRI, breast ultrasound, 
and other technologies for the detection of clinically occult breast cancer. Journal of the American College of Radiology, 7(1), 18-27. doi:10.1016/j.jacr.2009.09.022

Magnus, M. C., Ping, M., Shen, M. M., Bourgeois, J., \& Magnus, J. H. (2011). Effectiveness of mammography screening in reducing breast cancer mortality in women aged 39-49 years: A meta-analysis. Journal of Women's Health, 20(6), 845-852. doi:10.1089/jwh.2010.2098

Monticciolo, D. L., Newell, M. S., Hendrick, R. E., Helvie, M. A., Moy, L., Monsees, B., .. . Sickles, E. A. (2017). Breast cancer screening for average-risk women: Recommendations from the ACR commission on breast imaging. Journal of the American College of Radiology, 14(9), 1137-1143. doi:10.1016/j.jacr.2017.06.001

Moyer, V. A. (2014). Risk assessment, genetic counseling, and genetic testing for BRCA-related cancer in women: U.S. preventive services task force recommendation statement. Annals of Internal Medicine, 160(4), 271. doi:10.7326/M13-2747

Myers, E. R., Moorman, P., Gierisch, J. M., Havrilesky, L. J., Grimm, L. J., Ghate, S., . . Sanders, G. D. (2015). Benefits and harms of breast cancer screening: A systematic review. Jama, 314(15), 1615-1634. doi:10.1001/jama.2015.13183

National Cancer Institute. (n.d.). NCI dictionary of cancer terms. Retrieved from https://www.cancer.gov/publications/dictionaries/cancer-terms/def/overdiagnosis

National Women's Law Center (2013). Toolkit: Getting the coverage you deserve. What to do if you are charged a co-payment, deductible, or co-insurance for a preventative service. Retrieved from https://www.nwlc.org/sites/default/files/pdfs/final_nwlclogo_preventive servicestoolkit_9-25-13.pdf

Nelson, H. D., Fu, R., Cantor, A., Pappas, M., Daeges, M., \& Humphrey, L. (2016a). Effectiveness of breast cancer screening: Systematic review and meta-analysis to update the 
2009 U.S. preventive services task force recommendation. Annals of Internal

Medicine, 164(4), 244. doi:10.7326/M15-0969

Nelson, H. D., Pappas, M., Cantor, A., Griffin, J., Daeges, M., \& Humphrey, L. (2016b). Harms of breast cancer screening: Systematic review to update the 2009 U.S. preventive services task force recommendation. Annals of Internal Medicine, 164(4), 256. doi:10.7326/M150970

New Choice Health. (2019). Oakland, CA: Breast mammogram (bilateral) cost comparison. Retrieved from https://www.newchoicehealth.com/places/california/oakland/ mammogram/breast-mammogram-both-breasts-mammogram

Oeffinger, K. C., Fontham, E. T. H., Etzioni, R., Herzig, A., Michaelson, J. S., Shih, Y. T., .. . Wender, R. (2015). Breast cancer screening for women at average risk: 2015 guideline update from the american cancer society. Jama, 314(15), 1599-1614.

doi:10.1001/jama.2015.12783

Office of Disease Prevention and Health Promotion. (2018). Cancer. Retrieved from https://www.healthypeople.gov/2020/topics-objectives/topic/cancer

Pace, L. E., \& Keating, N. L. (2014). A systematic assessment of benefits and risks to guide breast cancer screening decisions. Jama, 311(13), 1327-1335. doi:10.1001/jama.2014.1398

Radhakrishnan, A., Nowak, S. A., Parker, A. M., Visvanathan, K., \& Pollack, C. E. (2017). Physician breast cancer screening recommendations following guideline changes: Results of a national survey. JAMA Internal Medicine, 177(6), 877-878. doi:10.1001/jamainternmed.2017.0453

Shen, N., Hammonds, L., Madsen, D., \& Dale, P. (2011). Mammography in 40-year-old women: What difference does it make? the potential impact of the U.S. preventative services task 
force (USPSTF) mammography guidelines. Annals of Surgical Oncology, 18(11), 30663071. doi:10.1245/s10434-011-2009-4

Siu, A. L. (2016). Screening for breast cancer: U.S. preventive services task force recommendation statement. Annals of Internal Medicine, 164(4), 279. doi:10.7326/M152886

Surveillance, Epidemiology, and End Results Program (n.d.). Cancer stat facts: Female breast cancer. Retrieved from https://seer.cancer.gov/statfacts/html/breast.html

United States Preventive Services Task Force. (2019). Final recommendation statement: Breast cancer: Screening. Retrieved from https://www.uspreventiveservicestaskforce.org/Page/ Document/RecommendationStatementFinal/breast-cancer-screening1

van den Ende, C., Oordt-Speets, A. M., Vroling, H., \& van Agt, Heleen M. E. (2017). Benefits and harms of breast cancer screening with mammography in women aged 40-49 years: A systematic review. International Journal of Cancer, 141(7), 1295-1306. doi:10.1002/ijc.30794

World Health Organization (2018). Breast cancer: Prevention and control. Retrieved from http://www.who.int/cancer/detection/breastcancer/en/index1.html

Yabroff, K. R., Lund, J., Kepka, D., \& Mariotto, A. (2011). Economic burden of cancer in the united states: Estimates, projections, and future research. Cancer Epidemiology, Biomarkers \& Prevention: A Publication of the American Association for Cancer Research, Cosponsored by the American Society of Preventive Oncology, 20(10), 20062014. doi:10.1158/1055-9965.EPI-11-0650 


\section{Section VIII. Appendices}

Appendix A: DNP Statement of Non-Research Determination

\section{DNP Statement of Non-Research Determination Form}

\section{Student Name: _Lacrisha Go}

Title of Project: Standardizing Mammogram Screening in Primary Care: Integrating an Evidence Based Approach

Brief Description of Project: Mammogram screening practices for breast cancer vary between initial start age, frequency, and discontinuation among reputable organizations. Both modifiable and non-modifiable risk factors has caused even further confusion in the screening process. This has consequently resulted in inconsistent provider practices within primary care and ultimately impacted early identification of breast cancer and its mortality. The purpose of this project is to create and implement a breast cancer screening algorithm for providers in primary care to identify, assess, collaborate, and refer women for mammogram testing using the appropriate guidelines and risk factor assessments based on age.

A) Aim Statement: By March 2018, primary care providers at the Federally Qualified Health Center (FQHC) will utilize a standardized approach for routine screening mammograms using the Screening Mammogram Initiation Protocol (SMIP).

B) Description of Intervention: The DNP student will create the SMIP and lead an educational training session to FQHC health care providers and medical assistants about the breast cancer mammogram screening algorithm. Participants will utilize the information taught in the presentation to effectively implement and utilize the toolkit into practice. Six weeks after initial project implementation, the DNP student will connect with project manager to collect statistical information from I2I tracking and evaluate intervention's effectiveness from completed staff surveys.

C) How will this intervention change practice? This intervention will reduce missed opportunities of initial screening by standardizing the breast cancer screening process for all female patients at FQHC. It will help increase health care provider knowledge and empowerment to counsel and encourage collaboration of comprehensive plans with their patient.

D) Outcome measurements: 1) At least $80 \%$ of providers will increase their knowledge of when and how to counsel female members about breast health. 2) At least 25 patients will receive counseling/recommendation for mammogram using the SMIP starting at age 40.3) At least $50 \%$ of the providers will acknowledge satisfaction 
with utilizing the SMIP algorithm for breast cancer screening.

To qualify as an Evidence-based Change in Practice Project, rather than a Research Project, the criteria outlined in federal guidelines will be used:

(http://answers.hhs.gov/ohrp/categories/1569)

$\mathbf{X}$ This project meets the guidelines for an Evidence-based Change in Practice Project as outlined in the Project Checklist (attached). Student may proceed with implementation.

$\square$ This project involves research with human subjects and must be submitted for IRB approval before project activity can commence.

Comments:

\section{EVIDENCE-BASED CHANGE OF PRACTICE PROJECT CHECKLIST *}

Instructions: Answer YES or NO to each of the following statements:

\begin{tabular}{|l|c|c|}
\hline Project Title: & YES & NO \\
\hline $\begin{array}{l}\text { The aim of the project is to improve the process or delivery of care with } \\
\text { established/ accepted standards, or to implement evidence-based change. There is } \\
\text { no intention of using the data for research purposes. }\end{array}$ & $\mathbf{X}$ & \\
\hline $\begin{array}{l}\text { The specific aim is to improve performance on a specific service or program and is } \\
\text { a part of usual care. ALL participants will receive standard of care. }\end{array}$ & $\mathbf{X}$ & \\
\hline $\begin{array}{l}\text { The project is NOT designed to follow a research design, e.g., hypothesis testing } \\
\text { or group comparison, randomization, control groups, prospective comparison } \\
\text { groups, cross-sectional, case control). The project does NOT follow a protocol that } \\
\text { overrides clinical decision-making. }\end{array}$ & $\mathbf{X}$ & \\
\hline $\begin{array}{l}\text { The project involves implementation of established and tested quality standards } \\
\text { and/or systematic monitoring, assessment or evaluation of the organization to } \\
\text { ensure that existing quality standards are being met. The project does NOT } \\
\text { develop paradigms or untested methods or new untested standards. }\end{array}$ & $\mathbf{X}$ & \\
\hline $\begin{array}{l}\text { The project involves implementation of care practices and interventions that are } \\
\text { consensus-based or evidence-based. The project does NOT seek to test an } \\
\text { intervention that is beyond current science and experience. }\end{array}$ & $\mathbf{X}$ & \\
\hline $\begin{array}{l}\text { The project is conducted by staff where the project will take place and involves } \\
\text { staff who are working at an agency that has an agreement with USF SONHP. }\end{array}$ & $\mathbf{X}$ & \\
\hline $\begin{array}{l}\text { The project has NO funding from federal agencies or research-focused } \\
\text { organizations and is not receiving funding for implementation research. }\end{array}$ & $\mathbf{X}$ \\
\hline $\begin{array}{l}\text { The agency or clinical practice unit agrees that this is a project that will be } \\
\text { implemented to improve the process or delivery of care, i.e., not a personal } \\
\text { research project that is dependent upon the voluntary participation of colleagues, } \\
\text { students and/ or patients. }\end{array}$ & $\mathbf{X}$ & \\
\hline $\begin{array}{l}\text { If there is an intent to, or possibility of publishing your work, you and supervising } \\
\text { faculty and the agency oversight committee are comfortable with the following }\end{array}$ & $\mathbf{X}$ & \\
\hline
\end{tabular}


statement in your methods section: "This project was undertaken as an Evidencebased change of practice project at X hospital or agency and as such was not formally supervised by the Institutional Review Board."

ANSWER KEY: If the answer to ALL of these items is yes, the project can be considered an Evidence-based activity that does NOT meet the definition of research. IRB review is not required. Keep a copy of this checklist in your files. If the answer to ANY of these questions is NO, you must submit for IRB approval.

*Adapted with permission of Elizabeth L. Hohmann, MD, Director and Chair, Partners Human Research Committee, Partners Health System, Boston, MA.

STUDENT NAME (Please print):

Lacrisha J. Go.

Signature of Student:

DATE

SUPERVISING FACULTY MEMBER (CHAIR) NAME (Please print):

Signature of Supervising Faculty Member (Chair):

DATE 
Appendix B: Letter of Support from Organization

Sun, Feb 10, 8:09 PM (2 days ago)

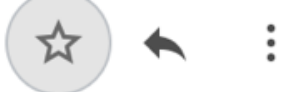

to $\mathrm{me}-$

Hi Lacrisha,

I am very excited to have you implement your DNP Project at

Center. I give you full permission to work with me this semester on your DNP project of Standardizing Mammogram Screening in Primary Care. You have my complete support.

Please include this email in your prospectus as your official permission statement.

Sincerely,

CONFIDENTIALITY NOTICE:

This electronic mail transmission may contain privileged and/or confidential information only for use by the intended recipients. Any use, distribution, copying or disclosure by any person, other than the intended recipients is strictly prohibited and may be subject to civil action and/or criminal penalties. If you received this transmission in error, please notify the sender by reply e-mail or by telephone and delete the transmission. 
Appendix C: Evaluation Table

\begin{tabular}{|c|c|c|c|c|c|c|}
\hline Citation & $\begin{array}{l}\text { Design/Method/ } \\
\text { Measure }\end{array}$ & $\begin{array}{c}\text { Sample } \\
\& \\
\text { Setting }\end{array}$ & $\begin{array}{c}\text { Variables } \\
\text { Studied and } \\
\text { Their Definitions }\end{array}$ & $\begin{array}{c}\text { Data } \\
\text { Analysis }\end{array}$ & Findings & $\begin{array}{c}\text { Appraisal: Worth to } \\
\text { Practice }\end{array}$ \\
\hline $\begin{array}{l}\text { Magnus } \\
\text { et al., } \\
2011\end{array}$ & $\begin{array}{l}\text { A meta-analysis } \\
\text { evaluating BCS } \\
\text { mortality for women } \\
\text { aged 39-49. Sources } \\
\text { reviewed (August } \\
\text { 2009-December 2009) } \\
\text { using the Cochrane, } \\
\text { Educational Resources } \\
\text { Information Center, } \\
\text { Medline, Ovid, and } \\
\text { PubMed databases. } \\
\text { Quality of evidence } \\
\text { evaluated by two, } \\
\text { independent } \\
\text { reviewers. }\end{array}$ & $\begin{array}{l}\text { Nine } \\
\text { randomi } \\
\text { zed } \\
\text { controlle } \\
\text { d trials } \\
\text { included }\end{array}$ & $\begin{array}{c}\text { IV: Age } \\
\text { DV: Breast } \\
\text { cancer diagnosis } \\
\text { and mortality }\end{array}$ & $\begin{array}{l}\text { DerSimonia } \\
\mathrm{n} \text { and Laird } \\
\text { random } \\
\text { effects } \\
\text { model using } \\
\text { the STATA } \\
\text { statistical } \\
\text { software } \\
\text { version } \\
10.1 .\end{array}$ & $\begin{array}{c}\text { Breast cancer } \\
\text { mortality reduction } \\
\text { found with women } \\
\text { aged 39-49 receiving } \\
\text { routine } \\
\text { mammography. }\end{array}$ & $\begin{array}{l}\text { Implications: Evidence } \\
\text { suggests that women } \\
\text { younger than } 50 \text { years- } \\
\text { old experience a } \\
\text { reduced incidence of } \\
\text { breast cancer mortality } \\
\text { with mammogram } \\
\text { screening. } \\
\text { Limitations: All } \\
\text { studies evaluated were } \\
\text { conducted >10 years } \\
\text { ago reflecting possible } \\
\text { outdated imaging } \\
\text { modality and treatment } \\
\text { options. } \\
\text { LOE: I }\end{array}$ \\
\hline $\begin{array}{l}\text { Myers et } \\
\text { al., } 2015\end{array}$ & $\begin{array}{l}\text { Systematic review of } \\
\text { available evidence on } \\
\text { the harms and benefits } \\
\text { of breast cancer } \\
\text { screening. Sources } \\
\text { reviewed (September } \\
2013 \text { and March 2014) } \\
\text { using CINAHL, } \\
\text { PyschINFO, and } \\
\text { PubMed databases. }\end{array}$ & $\begin{array}{l}\text { Ten } \\
\text { randomi } \\
\text { zed } \\
\text { controlle } \\
\text { d trials, } \\
72 \\
\text { observat } \\
\text { ional } \\
\text { studies, } \\
\text { one }\end{array}$ & $\begin{array}{c}\text { IV: Age, } \\
\text { mammography, } \\
\text { clinical breast } \\
\text { examinations } \\
\text { DV: Breast } \\
\text { cancer mortality, } \\
\text { overdiagnosis, } \\
\text { life expectancy, }\end{array}$ & $\begin{array}{l}\text { Summary } \\
\text { estimates, } \\
\text { qualitative } \\
\text { synthesis }\end{array}$ & $\begin{array}{l}\text { "Moderate" quality of } \\
\text { evidence that } \\
\text { mammography } \\
\text { screening is correlated } \\
\text { with mortality } \\
\text { reduction for women } \\
\text { ages } 40-69 \text { and an } \\
\text { increase in false- } \\
\text { positive results with } \\
\text { recommendation for }\end{array}$ & $\begin{array}{l}\text { Implications: Based on } \\
\text { variability and the } \\
\text { quality of available } \\
\text { evidence it is difficult } \\
\text { to determine which } \\
\text { breast cancer } \\
\text { screening } \\
\text { recommendation } \\
\text { should be followed. }\end{array}$ \\
\hline
\end{tabular}




\begin{tabular}{|c|c|c|c|c|c|c|}
\hline & $\begin{array}{l}\text { Quality of evidence } \\
\text { evaluated using the } \\
\text { Grading of } \\
\text { Recommendations } \\
\text { Assessment, } \\
\text { Development, and } \\
\text { Evaluation framework. }\end{array}$ & $\begin{array}{l}\text { modelin } \\
\text { g study, } \\
\text { and } \\
\text { seven } \\
\text { reviews }\end{array}$ & $\begin{array}{l}\text { quality-adjusted } \\
\text { life expectancy }\end{array}$ & & $\begin{array}{l}\text { biopsy over } 10 \text { years } \\
\text { in the United States. } \\
\text { "Low" evaluation of } \\
\text { evidence found } \\
\text { between the best } \\
\text { intervals of screening, } \\
\text { overdiagnosis, quality- } \\
\text { adjusted life } \\
\text { expectancy, and } \\
\text { association with } \\
\text { clinical breast } \\
\text { examinations and } \\
\text { mortality. }\end{array}$ & $\begin{array}{l}\text { Limitations: No } \\
\text { publication date limit, } \\
\text { level of evidence, } \\
\text { varying screening } \\
\text { methods, } \\
\text { advancements in } \\
\text { treatment technology } \\
\text { since studies } \\
\text { conducted } \\
\text { LOE: III }\end{array}$ \\
\hline $\begin{array}{l}\text { Nelson } \\
\text { et al., } \\
2016 a\end{array}$ & $\begin{array}{l}\text { Update on the } 2009 \\
\text { USPSTF systematic } \\
\text { review with meta- } \\
\text { analysis on the } \\
\text { effectiveness of BCS. } \\
\text { Sources analyzed } \\
\text { (June, 2015) using } \\
\text { MEDLINE and } \\
\text { Cochrane databases. }\end{array}$ & $\begin{array}{l}\text { Thirty- } \\
\text { eight } \\
\text { articles } \\
\text { included } \\
\text { (Eight } \\
\text { randomi } \\
\text { zed } \\
\text { controlle } \\
\text { d trials) }\end{array}$ & $\begin{array}{l}\text { IV: Age, imaging } \\
\text { modalities } \\
\text { utilized } \\
\text { DV: Breast } \\
\text { cancer mortality, } \\
\text { stage of diagnosis } \\
\text { outcomes, and } \\
\text { all-cause } \\
\text { mortality }\end{array}$ & $\begin{array}{l}\text { Random } \\
\text { effects } \\
\text { modeling, } \\
\text { profile- } \\
\text { likelihood } \\
\text { modeling, } \\
\text { Cochran } \\
\text { chi-square } \\
\text { tests, } I^{2} \\
\text { statistic, } \\
\text { short and } \\
\text { long case } \\
\text { accrual } \\
\text { methods, } \\
\text { absolute rate } \\
\text { reduction, } \\
\text { Poisson } \\
\text { modeling, } \\
\text { and Stata/IC }\end{array}$ & $\begin{array}{l}\text { Increased breast } \\
\text { cancer mortality } \\
\text { reduction found as one } \\
\text { aged with routine } \\
\text { mammogram } \\
\text { screening in } \\
\text { randomized control } \\
\text { trials, however } \\
\text { different indications } \\
\text { indicated with two } \\
\text { observational studies. } \\
\text { All cause-mortality } \\
\text { was not found to be } \\
\text { significant among any } \\
\text { age. Advanced breast } \\
\text { cancer reduction } \\
\text { indicated to reduce for } \\
\text { women ages } 50 \text { and } \\
\text { over. }\end{array}$ & $\begin{array}{l}\text { Implications: Further } \\
\text { research is necessary } \\
\text { to help guide } \\
\text { screening practices } \\
\text { Limitations: No } \\
\text { publication date limit, } \\
\text { advancements in } \\
\text { treatment and imaging } \\
\text { technology since } \\
\text { studies conducted } \\
\text { LOE: I }\end{array}$ \\
\hline
\end{tabular}




\begin{tabular}{|c|c|c|c|c|c|c|}
\hline & & & & $\begin{array}{l}\text { version } 13.1 \\
\text { (StataCorp) }\end{array}$ & & \\
\hline $\begin{array}{l}\text { Nelson } \\
\text { et al., } \\
2016 b\end{array}$ & $\begin{array}{l}\text { Update on the } 2009 \\
\text { USPSTF systematic } \\
\text { review on the harms of } \\
\text { BCS. Sources } \\
\text { analyzed (December } \\
\text { 2014) using } \\
\text { MEDLINE and } \\
\text { Cochrane databases. }\end{array}$ & $\begin{array}{c}\text { Fifty- } \\
\text { nine } \\
\text { studies } \\
\text { included }\end{array}$ & $\begin{array}{l}\text { IV: Age } \\
\text { DV: False- } \\
\text { positives, } \\
\text { overdiagnosis, } \\
\text { radiation } \\
\text { exposure, pain, } \\
\text { anxiety }\end{array}$ & $\begin{array}{l}\text { Qualitative } \\
\text { synthesis }\end{array}$ & $\begin{array}{l}\text { False-positive rates } \\
\text { observed similarly for } \\
\text { women in the } 40 \text { and } \\
50 \text { ages, but overall } \\
\text { higher with women } \\
\text { ages } 40-49 \text { especially } \\
\text { with dense breast } \\
\text { tissue. Varying range } \\
\text { of overdiagnosis found } \\
\text { among all modeling } \\
\text { studies. Women with } \\
\text { false-positive findings } \\
\text { found with more } \\
\text { anxiety than women } \\
\text { with negative } \\
\text { mammography results. } \\
\text { Pain associated with } \\
\text { mammography varied. } \\
\text { No studies found a } \\
\text { direct association with } \\
\text { radiation induced } \\
\text { breast cancer from } \\
\text { mammography } \\
\text { screening. }\end{array}$ & $\begin{array}{c}\text { Implications: Women } \\
\text { with more breast dense } \\
\text { tissue and are receive } \\
\text { mammography } \\
\text { annually are more } \\
\text { likely to receive false- } \\
\text { positive results leading } \\
\text { to additional imaging. } \\
\text { Overdiagnosis is } \\
\text { difficult to determine } \\
\text { because there is no } \\
\text { standard of } \\
\text { measurement. } \\
\text { Psychological impact } \\
\text { is a subjective finding, } \\
\text { and the effects on each } \\
\text { women differs. } \\
\text { Limitations: Differing } \\
\text { screening practices, } \\
\text { patient populations, } \\
\text { modeling parameters } \\
\text { (i.e. DCIS diagnosis, } \\
\text { BC incidence) } \\
\text { LOE: III }\end{array}$ \\
\hline
\end{tabular}




\begin{tabular}{|c|c|c|c|c|c|c|}
\hline $\begin{array}{c}\text { Oeffinge } \\
\text { r, et al., } \\
2015\end{array}$ & $\begin{array}{l}\text { Systematic review of } \\
\text { current BCS literature } \\
\text { conducted by the } \\
\text { Duke University } \\
\text { Evidence Synthesis } \\
\text { Group. Quality of } \\
\text { evidence evaluated } \\
\text { using the Grading of } \\
\text { Recommendations } \\
\text { Assessment, } \\
\text { Development, and } \\
\text { Evaluation framework } \\
\text { by the ACS's } \\
\text { guideline development } \\
\text { group. }\end{array}$ & $\begin{array}{c}\text { Not } \\
\text { clearly } \\
\text { delineat } \\
\text { ed }\end{array}$ & $\begin{array}{c}\text { IV: Age of } \\
\text { diagnosis } \\
\text { DV: Breast } \\
\text { cancer mortality, } \\
\text { life expectancy, } \\
\text { false positives, } \\
\text { overdiagnosis, } \\
\text { quality of life, } \\
\text { tumor burden }\end{array}$ & $\begin{array}{c}\text { Qualitative } \\
\text { synthesis }\end{array}$ & $\begin{array}{l}\text { High quality strength } \\
\text { for breast cancer } \\
\text { mortality reduction in } \\
\text { women receiving } \\
\text { mammography } \\
\text { screening younger } \\
\text { than } 50 \text { years. False } \\
\text { positives found higher } \\
\text { with screening } \\
\text { annually than } \\
\text { biennially. The quality } \\
\text { of evidence estimating } \\
\text { overdiagnosis, life } \\
\text { expectancy with } \\
\text { screening, and quality- } \\
\text { adjusted life } \\
\text { expectancy was } \\
\text { considered low. }\end{array}$ & $\begin{array}{c}\text { Implications: } \\
\text { Grading of outcomes } \\
\text { vary between studies } \\
\text { and weigh harms } \\
\text { versus benefits } \\
\text { differently. } \\
\text { Recommendations by } \\
\text { ACS are a guidance, } \\
\text { but shared-decision } \\
\text { making is vital } \\
\text { between the provider } \\
\text { and the patient. } \\
\text { Limitations: Many } \\
\text { factors of each } \\
\text { individual study } \\
\text { affecting outcomes } \\
\text { (i.e. comparison of } \\
\text { age-groups, imaging } \\
\text { modality utilized, type } \\
\text { of screening, patient } \\
\text { population risk } \\
\text { factors), and outcomes } \\
\text { of evidence were } \\
\text { evaluated differently } \\
\text { to determine } \\
\text { recommendation (i.e. } \\
\text { modeling estimates, } \\
\text { empirical } \\
\text { comparisons) } \\
\text { LOE: III }\end{array}$ \\
\hline
\end{tabular}




\begin{tabular}{|c|c|c|c|c|c|c|}
\hline $\begin{array}{c}\text { Pace \& } \\
\text { Keating, } \\
2014\end{array}$ & $\begin{array}{l}\text { Systematic review of } \\
\text { harms and benefits of } \\
\text { BCS. Sources } \\
\text { analyzed using } \\
\text { Medline database and } \\
\text { manual search of } \\
\text { reference lists and } \\
\text { current practice } \\
\text { recommendations. } \\
\text { Quality of evidence } \\
\text { evaluated using the } \\
\text { American Heart } \\
\text { Association } \\
\text { guidelines. }\end{array}$ & $\begin{array}{c}\text { Five } \\
\text { meta- } \\
\text { analyses } \\
\text { included } \\
\text { to } \\
\text { evaluate } \\
\text { BCS and } \\
\text { mortalit } \\
\text { y } \\
\text { reductio } \\
\mathrm{n},\end{array}$ & $\begin{array}{c}\text { IV: Age, } \\
\text { individual risk } \\
\text { factors of high } \\
\text { risk patients } \\
\text { DV: Breast } \\
\text { cancer mortality, } \\
\text { harms of } \\
\text { mammography } \\
\text { screening (false- } \\
\text { positives and } \\
\text { recommendation } \\
\text { for biopsy, } \\
\text { overdiagnosis), } \\
\text { and how to } \\
\text { support patients } \\
\text { in making } \\
\text { informed } \\
\text { decisions about } \\
\text { their breast health }\end{array}$ & $\begin{array}{l}\text { Qualitative } \\
\text { synthesis }\end{array}$ & $\begin{array}{l}\text { Mammography found } \\
\text { to decrease BC } \\
\text { mortality and found } \\
\text { significant for women } \\
\text { in their } 40 \text { through } 60 \\
\text { year ages. Evidence } \\
\text { shows there is a risk of } \\
\text { false-positives that is } \\
\text { higher the younger the } \\
\text { age. Overdiagnosis } \\
\text { estimates vary } \\
\text { between studies and } \\
\text { reports may be over or } \\
\text { underestimated. } \\
\text { Clinical decision } \\
\text { models can be used to } \\
\text { help best navigate best } \\
\text { clinical outcomes and } \\
\text { informed patient } \\
\text { decisions. }\end{array}$ & $\begin{array}{l}\text { Implications: Further } \\
\text { high, rigorous studies } \\
\text { needed to understand } \\
\text { true benefit/harm of } \\
\text { mammography. BCS } \\
\text { ought to be } \\
\text { individualized based } \\
\text { on risk factors and } \\
\text { patient priorities. } \\
\text { Limitations: } \\
\text { Publication date of } \\
\text { sources vary up to >10 } \\
\text { years ago, } \\
\text { advancements in } \\
\text { treatment and imaging } \\
\text { technology since } \\
\text { studies conducted. } \\
\text { LOE: III }\end{array}$ \\
\hline $\begin{array}{l}\text { Shen et } \\
\text { al., } 2011\end{array}$ & $\begin{array}{l}\text { A 10-year } \\
\text { retrospective chart } \\
\text { review through the } \\
\text { Cancer Registry } \\
\text { Database at an } \\
\text { unidentified institution } \\
\text { for women ages 40-49 } \\
\text { treated for BC that } \\
\text { followed the } \\
\text { Commission on } \\
\text { Cancer Programs } \\
\text { Standards. }\end{array}$ & $\begin{array}{c}1,581 \\
\text { females } \\
\text { treated } \\
\text { for BC, } \\
311 \text { ages } \\
40-49\end{array}$ & $\begin{array}{c}\text { IV: Age, annual } \\
\text { mammography } \\
\text { detected cancer, } \\
\text { non- } \\
\text { mammography } \\
\text { detected cancer } \\
\text { DV: Breast } \\
\text { cancer diagnosis, } \\
\text { tumor } \\
\text { size/sentinel } \\
\text { lymph node } \\
\text { involvement at }\end{array}$ & $\begin{array}{c}\text { Descriptive, } \\
\text { statistical } \\
\text { analysis }\end{array}$ & $\begin{array}{c}\text { Women with } \\
\text { mammography } \\
\text { detected cancer were } \\
\text { found to have at } \\
\text { diagnosis smaller } \\
\text { tumor size, less } \\
\text { sentinel lymph node } \\
\text { involvement, higher } \\
\text { disease-free and better } \\
\text { overall survival rates } \\
\text { compared with women } \\
\text { with non- }\end{array}$ & $\begin{array}{c}\text { Implications: Multiple } \\
\text { benefits of annual } \\
\text { mammography for } \\
\text { women starting at age } \\
40 \text { exhibited. } \\
\text { Limitations: Study } \\
\text { conducted > } 10 \text { years } \\
\text { ago } \\
\text { LOE: III }\end{array}$ \\
\hline
\end{tabular}




\begin{tabular}{|c|c|c|c|c|c|c|}
\hline & & & $\begin{array}{c}\text { diagnosis, } \\
\text { disease-free rate, } \\
\text { survival rate }\end{array}$ & & $\begin{array}{l}\text { mammography } \\
\text { detected cancer }\end{array}$ & \\
\hline $\begin{array}{l}\text { Van den } \\
\text { Ende et } \\
\text { al., } 2017\end{array}$ & $\begin{array}{l}\text { Systematic review of } \\
\text { the harms and benefits } \\
\text { of BCS for women } \\
\text { ages 40-49. Sources } \\
\text { analyzed (February } \\
\text { 2017) using Embase, } \\
\text { Medline, PubMed, and } \\
\text { Cochrane databases. } \\
\text { Quality of evidence } \\
\text { evaluated using the } \\
\text { Grading of } \\
\text { Recommendations } \\
\text { Assessment, } \\
\text { Development, and } \\
\text { Evaluation framework. }\end{array}$ & $\begin{array}{l}\text { Four } \\
\text { articles } \\
\text { examine } \\
\text { d of two } \\
\text { randomi } \\
\text { ze } \\
\text { controlle } \\
\text { d trials }\end{array}$ & $\begin{array}{c}\text { IV: Age } \\
\text { DV: Breast } \\
\text { cancer mortality, } \\
\text { all-cause } \\
\text { mortality, false- } \\
\text { positives, } \\
\text { overdiagnosis }\end{array}$ & $\begin{array}{l}\text { Qualitative } \\
\text { synthesis }\end{array}$ & $\begin{array}{l}\text { Breast cancer } \\
\text { reduction and all- } \\
\text { cause mortality not } \\
\text { found generalizable } \\
\text { and graded as } \\
\text { "moderate" quality of } \\
\text { evidence. False } \\
\text { positive recall } \\
\text { observed and } \\
\text { considered "high" } \\
\text { quality of evidence for } \\
\text { women ages 40-49. } \\
\text { Overdiagnosis based } \\
\text { on estimates. }\end{array}$ & $\begin{array}{l}\text { Implications: More } \\
\text { rigorous randomized } \\
\text { controlled trails } \\
\text { needed } \\
\text { Limitations: } \\
\text { Randomization } \\
\text { contamination, pre- } \\
\text { screened participants, } \\
\text { study generalizability, } \\
\text { all studies conducted } \\
\text { outside the United } \\
\text { States (differing } \\
\text { screening practices of } \\
\text { invitation to screen } \\
\text { versus opportunity to } \\
\text { screen) } \\
\text { LOE: III }\end{array}$ \\
\hline
\end{tabular}

Key: LOE: level of evidence (Johns Hopkins Hospital/The Johns Hopkins University, 2012a, 2012b), IV: Independent variable, DV: Dependent variable, BC: Breast cancer, BCS: Breast cancer screening 


\section{Appendix D: Gap Analysis Interview with lead Nurse Practitioner}

1. What are some existing standards of practice policies that you believe can be improved at FQHC?

There is a lot of current evidence-based literature that can update and improve our health care outcomes of our patients at the FQHC. The name of this clinic indicates a huge opportunity to work with vulnerable populations where we can provide comprehensive, thorough care to those with many health care needs. Improvements especially for funding of our clinic include preventative health and secondary services such as screening for hepatitis, HIV, TB, breast/cervical/colon cancer. Especially as DNP students, we have the access and tools to make really positive change at a clinic like this.

2. What is the current process of identifying, managing, and follow-up for this practice and existing health outcomes?

The current process of breast cancer screening is our Medical Assistants print out a sheet of all our patients scheduled for the next clinic day. On this list, our I2I Tracking system alerts which patient are in need of a preventative health or screening service. From this, patients are notified by our panel manager that they are being referred for a mammogram. Patients call the number on the referral and then obtain their mammogram at local outside facilities. Reports are sent to their primary provider who then follow-up with the patient of the results. Our standard of practice policy follows the USPSTF guidelines, but unremarkable radiology imaging reports recommend to rescreen yearly. Our policy that is adopted from the USPSTF recommends to screen every two years. It is also confusing when we should start screening for patients with risk factors and why some women with no significant risk factors are receiving mammograms younger than age 50 .

3. Is there available data that can support for the opportunity in change in practice?

I2I Tracks is a great system used to extract our data from NextGen to help track and indicate what preventative health measures are needed for each patient and reflects our compliance rates at the clinic. Using I2I Tracks we are able to measure baseline data, interventions that have been implemented at the clinic, and evaluate their effectiveness.

4. What are the desired outcomes for this practice change?

Outcomes of improving screening rates among all the providers would help maintain and possibly increase our Community Health Center Network government funding for our lowincome clinic at FQHC. It would improve health outcomes for our patients and provider satisfaction knowing we are providing the best available care current literature offers. 
Appendix E: Gap Analysis

\begin{tabular}{|l|l|l|}
\hline \multicolumn{3}{|c|}{ Gap Analysis } \\
\hline \multicolumn{1}{|c|}{ Desired Situation } & \multicolumn{1}{|c|}{ Current Situation } & \multicolumn{1}{c|}{ Action Plan } \\
\hline $\begin{array}{l}\text { Optimize the breast cancer } \\
\text { mammogram screening } \\
\text { process to improve overall } \\
\text { breast health for women at } \\
\text { FQHC clinics. }\end{array}$ & $\begin{array}{l}\text { FQHC follows the } \\
\text { USPSTF } \\
\text { recommendations on } \\
\text { breast cancer } \\
\text { mammogram } \\
\text { screening starting at } \\
\text { age 50 for all women, } \\
\text { however, evidence } \\
\text { suggests other options } \\
\text { available. }\end{array}$ & $\begin{array}{l}\text {-Perform literature review on current } \\
\text { guidelines and best available } \\
\text { evidence } \\
\text {-Create Screening Mammogram } \\
\text { Initiation Protocol (SMIP) } \\
\text {-Present project proposal to DNP } \\
\text { chair for approval }\end{array}$ \\
& $\begin{array}{l}\text {-Present project proposal to Site } \\
\text {-Provide PowerPoint presentation in- } \\
\text { service to FQHC staff } \\
\text {-Implement SMIP for 6-weeks } \\
\text {-Collect, analyze, evaluate, and } \\
\text { disseminate findings }\end{array}$ \\
\hline
\end{tabular}


Appendix F: GANTT Chart

\begin{tabular}{|c|c|c|c|c|c|c|c|c|c|c|c|c|c|}
\hline \multicolumn{14}{|c|}{ Project GANTT } \\
\hline & \multicolumn{6}{|c|}{2018} & \multicolumn{7}{|c|}{2019} \\
\hline Task/Description & $\Xi$ & $\sum_{Z}^{000}$ & 巳ి & $\overline{0}$ & $\begin{array}{l}\text { z } \\
\text { z }\end{array}$ & ப̊ & ‡ & e & $\sum^{\text {సี }}$ & 荎 & $\vec{\Xi}$ & $\Xi$ & $\Xi$ \\
\hline $\begin{array}{c}\text { Survey and } \\
\text { identify needs of } \\
\text { FQHC's clinic for } \\
\text { potential project }\end{array}$ & & & & & & & & & & & & & \\
\hline $\begin{array}{l}\text { Analyze current } \\
\text { recommendations } \\
\text { and complete } \\
\text { literature review }\end{array}$ & & & & & & & & & & & & & \\
\hline Create algorithm & & & & & & & & & & & & & \\
\hline $\begin{array}{l}\text { Collaborate with } \\
\text { stakeholders to } \\
\text { introduce project }\end{array}$ & & & & & & & & & & & & & \\
\hline $\begin{array}{c}\text { Provide } \\
\text { educational } \\
\text { training for } \\
\text { healthcare } \\
\text { providers and } \\
\text { medical assistants }\end{array}$ & & & & & & & & & & & & & \\
\hline Implement project & & & & & & & & & & & & & \\
\hline $\begin{array}{l}\text { Collect data and } \\
\text { analyze }\end{array}$ & & & & & & & & & & & & & \\
\hline $\begin{array}{l}\text { Disseminate } \\
\text { findings }\end{array}$ & & & & & & & & & & & & & \\
\hline $\begin{array}{l}\text { Complete written } \\
\text { DNP project }\end{array}$ & & & & & & & & & & & & & \\
\hline
\end{tabular}


Appendix G: Work Breakdown Structure

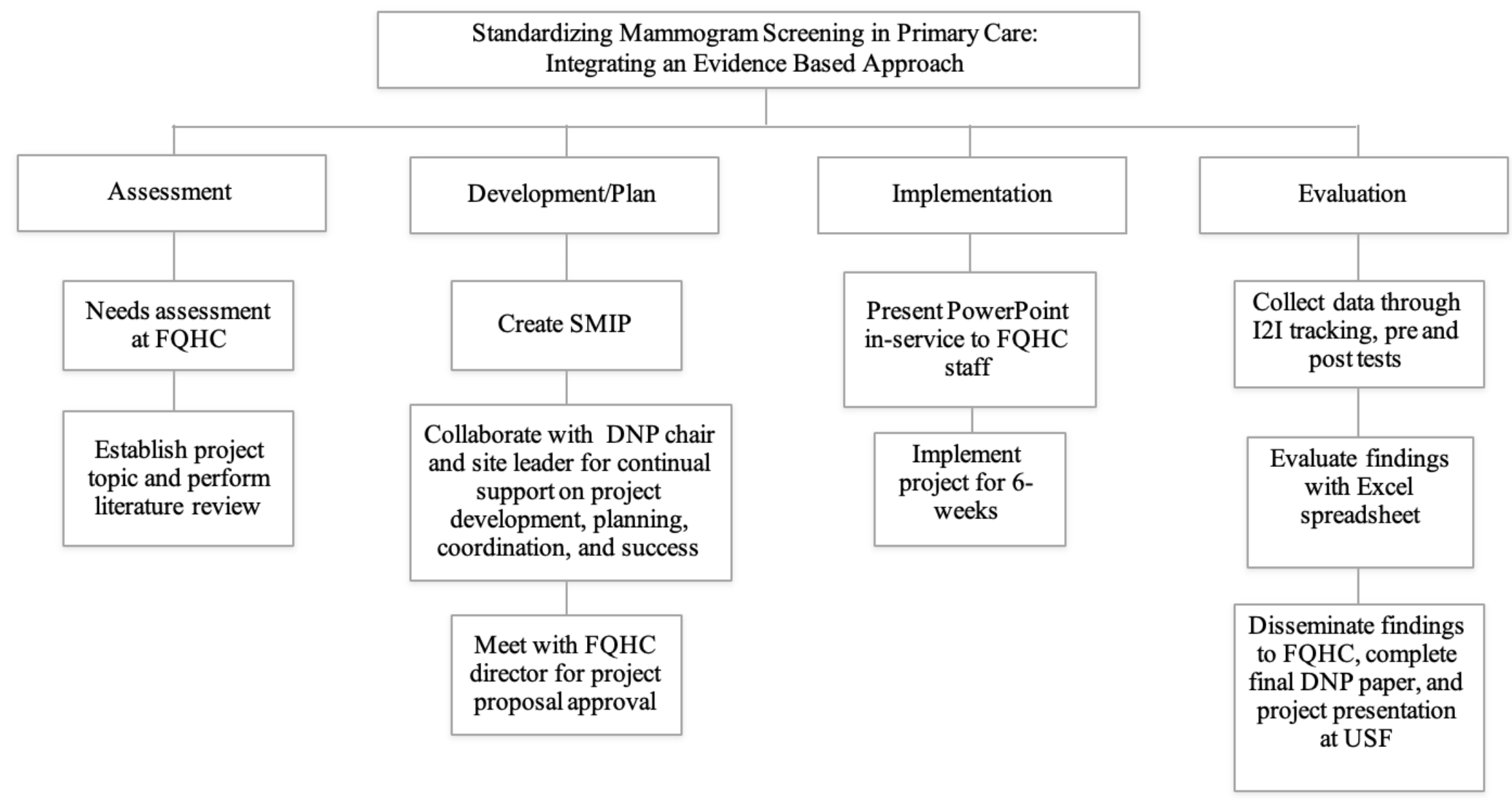




\section{Appendix H: SWOT Analysis}

\begin{tabular}{|c|c|}
\hline Strengths & Weaknesses \\
\hline $\begin{array}{l}\text { Health care professionals have } \\
\text { expressed a need to better identify, } \\
\text { address, and counsel on breast cancer } \\
\text { screening and referral for mammogram } \\
\text { at the FQHC } \\
\text { - Increase provider involvement, } \\
\text { knowled ge, and empowerment } \\
\text { - Increase patient satisfaction scores in } \\
\text { receiving comprehensive health } \\
\text { coverage } \\
\text { - Provide early detection, diagnosis, and } \\
\text { breast cancer treatment } \\
\text { Cost effective with ongoing } \\
\text { surveillance, prevention, and early } \\
\text { detection }\end{array}$ & $\begin{array}{l}\text { - No toolkit currently exists that } \\
\text { incorporates current evidence of best } \\
\text { practices on breast cancer mammogram } \\
\text { screening from reputable institutions } \\
\text { and government agency } \\
\text { - Resistance from medical assistants } \\
\text { and/or health care providers that there is } \\
\text { too little time or not as high of a priority } \\
\text { to implement during visit } \\
\text { - Lack of opportunity to use breast cancer } \\
\text { mammogram algorithm within time } \\
\text { frame of project } \\
\text { - The FQHC already follows the } \\
\text { USPSTF's grade "A" and "B" } \\
\text { guidelines for breast cancer screening }\end{array}$ \\
\hline Opportunities & Threats \\
\hline $\begin{array}{l}\text { - Increase quality of care and optimize } \\
\text { breast health outcomes with female } \\
\text { patients } \\
\text { - Meets Healthy People } 2020 \text { goals } \\
\text { towards reducing health disparities, } \\
\text { cancer related disability and mortality } \\
\text { - Standardize breast cancer policy and } \\
\text { procedure screening in primary care } \\
\text { - Decrease morbidity and mortality rates } \\
\text { especially among a high-risk population } \\
\text { - Raises awareness and promotes early } \\
\text { detection, diagnosis, and treatment }\end{array}$ & $\begin{array}{l}\text { - Competing institutions and government } \\
\text { agency's recommend varying guidelines } \\
\text { on initial screening, frequency, and } \\
\text { discontinuation of mammograms } \\
\text { - Cultural/language barriers } \\
\text { - Misunderstandings of algorithm }\end{array}$ \\
\hline
\end{tabular}


Appendix I: Budget

\begin{tabular}{|c|c|c|}
\hline Description & Calculations & Total Cost \\
\hline Project Manager time & $(\$ 67.70 / \text { hour x } 135 \text { hours }=\$ 9,140.60)^{1}$ & $\begin{array}{c}\$ 0 \\
\text { (DNP student Project) }\end{array}$ \\
\hline $\begin{array}{l}\text { Provider time } \\
\text { (Includes time for } \\
\text { presentation, pre/post } \\
\text { surveys, and utilizing } \\
\text { toolkit) }\end{array}$ & $\begin{array}{c}(\$ 75.48 / \text { hour } \times 3 \text { hours } \times 6 \text { providers }= \\
\$ 1,358.69)^{3}\end{array}$ & $\$ 1,358.69$ \\
\hline Medical Assistant time & $\begin{array}{c}(\$ 23.25 / \text { hour } \times 3 \text { hours } \times 6 \text { medical } \\
\text { assistants }=\$ 418.50)^{4}\end{array}$ & $\$ 418.50$ \\
\hline $\begin{array}{c}\text { Printed Material } \\
\text { (handouts and toolkit) }\end{array}$ & $\$ 70$ & $\$ 70$ \\
\hline Food for in-service & $\$ 40$ & $\$ 40$ \\
\hline Space Rental & $\$ 0$ & $\$ 0$ \\
\hline Equipment & $\$ 0$ & $\$ 0$ \\
\hline Total Budget & & $\$ 1,887.19$ \\
\hline
\end{tabular}

1. Glassdoor. (2019a). Registered nurse salaries in San Francisco, California area. https://www.glassdoor.com/Salaries/sanfrancisco-registered-nurse-salary-SRCH_IL.0,13_IM759_KO14,30.htm

2. Glassdoor. (2019c). Family Nurse Practitioner salaries in San Francisco, California area. Retrieved from https://www.glassdoor.com/Salaries/san-francisco-family-nurse-practitioner-salary-SRCH_IL.0,13_IM759_KO14,39.htm 3. Glassdoor. (2019d). Certified medical assistant salaries in San Francisco, California area. Retrieved from https://www.glassdoor.com/Salaries/san-francisco-certified-medical-assistant-salary-SRCH_IL.0,13_IM759_KO14,41.htm

\begin{tabular}{|l|l|}
\hline \multicolumn{2}{|c|}{ Burden of Breast Cancer Disease to the United States Healthcare System } \\
\hline 2010 Cost Estimate for all Cancers & $\$ 124.5$ billion \\
\hline 2010 Cost Estimate for Breast Cancer & $\$ 16.5$ billion \\
\hline 2018 Projected New Breast Cancer Diagnosis & 266,120 (30\%- Leading) \\
\hline 2018 Projected Breast Cancer Deaths & $40,920(14 \%$ - Second highest) \\
\hline $2010-2014$ Breast Cancer Incidence in California State & 120.7 per 100,000 \\
\hline
\end{tabular}




\begin{tabular}{|l|l|}
\hline \multicolumn{2}{|c|}{ Estimated Cost of Breast Health for an Uninsured Female Patient } \\
\hline Average cost of mammogram per patient & $\$ 102$ \\
\hline Average total cost of breast cancer treatment per patient & $\$ 100,000$ \\
\hline
\end{tabular}

\begin{tabular}{|c|c|}
\hline \multicolumn{2}{|c|}{ Estimated Lifetime Cost of Mammograms for an Uninsured Female Patient Based off of } \\
\hline USPSTF & $\$ 1,224$ \\
\hline ACOG & $\$ 3,570$ \\
\hline ACR (if discontinued at age 75) & $\$ 3,570$ \\
\hline ACCS (if discontinued at age 75 annually) \\
\hline (if discontinued at age 75 and started biennially after 55) \\
\hline NCCN (if discontinued at 75) & $\$ 3,570$ \\
\hline
\end{tabular}


Appendix J: Communication Matrix

\begin{tabular}{|c|c|c|c|}
\hline Information & Audience & Time & Methods of Communication \\
\hline $\begin{array}{l}\text { Project planning and } \\
\text { coordination }\end{array}$ & $\begin{array}{l}\text { DNP Chair } \\
\text { Site Leader } \\
\text { DNP Student }\end{array}$ & $\begin{array}{l}\text { Weekly- } \\
\text { Biweekly }\end{array}$ & $\begin{array}{c}\text { Email } \\
\text { In-person } \\
\text { Phone }\end{array}$ \\
\hline Project modifications & $\begin{array}{c}\text { DNP Chair } \\
\text { DNP Student }\end{array}$ & As needed & $\begin{array}{c}\text { Email } \\
\text { In-person } \\
\text { Phone }\end{array}$ \\
\hline $\begin{array}{l}\text { Project issues and } \\
\text { resolutions }\end{array}$ & $\begin{array}{c}\text { DNP Chair } \\
\text { DNP Student }\end{array}$ & As needed & $\begin{array}{c}\text { Email } \\
\text { In-person } \\
\text { Phone }\end{array}$ \\
\hline Milestone completions & $\begin{array}{l}\text { DNP Chair } \\
\text { Site Leader } \\
\text { DNP Student }\end{array}$ & Monthly & $\begin{array}{c}\text { Email } \\
\text { In-person } \\
\text { Phone }\end{array}$ \\
\hline
\end{tabular}


Appendix K: Screening Mammogram Initiation Protocol (SMIP)

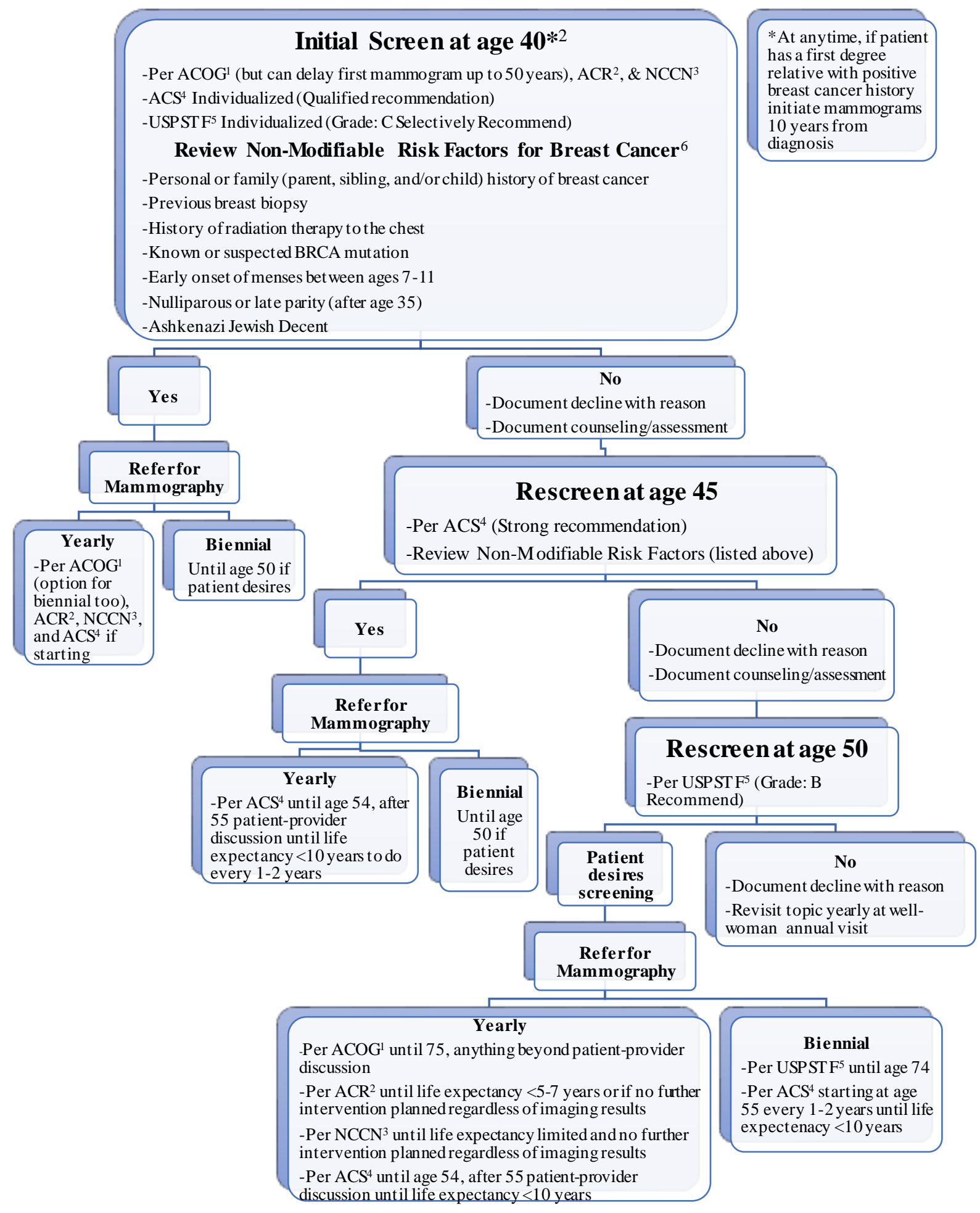


Adapted from:

\section{American College of Obstetrics and Gynecologists (ACOG)}

The American College of Obstetricians and Gynecologists. (2017). ACOG practice bulletin: Clinical management guidelines for obstetrician-gynecologists Retrieved from https://www.acog.org/Clinical-Guidance-and-Publications/Practice-Bulletins/Committee-onPractice-Bulletins-Gynecology/Breast-Cancer-Risk-Assessment-and-Screening-in-AverageRisk-Women?IsMobileSet=false

\section{American College of Radiology (ACR)}

Lee, C. H., Dershaw, D. D., Kopans, D., Evans, P., Monsees, B., Monticciolo, D., ... Burhenne, L. W. (2010). Breast cancer screening with imaging: Recommendations from the society of breast imaging and the ACR on the use of mammography, breast MRI, breast ultrasound, and other technologies for the detection of clinically occult breast cancer. Journal of the American College of Radiology, 7(1), 18-27. doi:10.1016/j.jacr.2009.09.022

Monticciolo, D. L., Newell, M. S., Hendrick, R. E., Helvie, M. A., Moy, L., Monsees, B., . . Sickles, E. A. (2017). Breast cancer screening for average-risk women: Recommendations from the ACR commission on breast imaging. Journal of the American College of Radiology, 14(9), 1137-1143. doi:10.1016/j.jacr.2017.06.001

\section{National Comprehensive Cancer Network (NCCN)}

Bevers, T. B., Helvie, M., Bonaccio, E., Calhoun, K. E., Daly, M. B., Farrar, W. B., . . Kumar, R. (2018). Breast cancer screening and diagnosis, version 3.2018, NCCN clinical practice guidelines in oncology. Journal of the National Comprehensive Cancer Network : JNCCN, 16(11), 1362-1389. doi:10.6004/jnccn.2018.0083

\section{American Cancer Society (ACS)}

Oeffinger, K. C., Fontham, E. T. H., Etzioni, R., Herzig, A., Michaelson, J. S., Shih, Y. T., .. . Wender, R. (2015). Breast cancer screening for women at average risk: 2015 guideline update from the American cancer society. Jama, 314(15), 1599-1614. doi:10.1001/jama.2015.12783

\section{United States Preventive Services Task Force (USPSTF)}

Siu, A. L. (2016). Screening for breast cancer: U.S. preventive services task force recommendation statement. Annals of Internal Medicine, 164(4), 279. doi:10.7326/M15-2886

6. National Institute of Health: National Cancer Institute. (n.d.). The breast cancer risk assessment tool. Retrieved from https://bcrisktool.cancer.gov 
Breast Cancer Screening Guidelines

\begin{tabular}{|c|c|c|c|}
\hline Group & $\begin{array}{l}\text { Age to Initiate } \\
\text { Mammograms }\end{array}$ & Frequency (years) & $\begin{array}{l}\text { Age to Discontinue } \\
\text { Mammograms }\end{array}$ \\
\hline $\mathrm{ACOG}^{1}$ & $\begin{array}{l}40 * \\
\text { No later than } 50\end{array}$ & $1-2 *$ & $\begin{array}{l}75 \text {, anything beyond is } \\
\text { provider-patient discussion }\end{array}$ \\
\hline $\mathrm{ACR}^{2}$ & 40 & 1 & $\begin{array}{c}\text { Life expectancy }<5-7 \text { years } \\
\text { or if no furtherintervention } \\
\text { planned regardless of } \\
\text { imaging results }\end{array}$ \\
\hline $\mathrm{ACS}^{3}$ & $\begin{array}{c}40-44 \\
\text { (Qualified Recommendation) } \\
45 \\
\text { (Strong Recommendation) }\end{array}$ & $\begin{array}{c}\text { 1: ages } 40-44 \text { if starting } \\
\text { (Qualified Recommendation) } \\
1 \text { : ages } 45-54 \\
\text { (Qualified Recommendation) } \\
\text { 1-2: age } \geq 55 \text { (Qualified } \\
\text { Recommendation) }\end{array}$ & $\begin{array}{c}\text { Life expectancy }<10 \text { years } \\
\text { (Qualified } \\
\text { Recommendation) }\end{array}$ \\
\hline $\mathrm{NCCN}^{4}$ & 40 & 1 & $\begin{array}{l}\text { Limited life expectancy } \\
\text { and no further intervention } \\
\text { planned regardless of } \\
\text { imaging results }\end{array}$ \\
\hline USPSTF $^{5}$ & $\begin{array}{c}40-49 \\
\text { (Grade C: Selectively } \\
\text { Recommend) } \\
50 \\
\text { (Grade B: Recommend) }\end{array}$ & $\begin{array}{c}2 \\
\text { (Grade B: Recommend) }\end{array}$ & $\begin{array}{c}74 \\
\text { (Grade B: Recommend) }\end{array}$ \\
\hline
\end{tabular}

Adapted from:

\section{American College of Obstetrics and Gynecologists (ACOG)}

The American College of Obstetricians and Gynecologists. (2017). ACOG practice bulletin: Clinical management guidelines for obstetrician-gynecologists Retrieved from https://www.acog.org/Clinical-Guidance-and-

Publications/Practice-Bulletins/Committee-on-Practice-Bulletins-Gynecology/Breast-Cancer-Risk-Assessment-andScreening-in-Average-Risk-Women?IsMobileSet=false

\section{American College of Radiology (ACR)}

Lee, C. H., Dershaw, D. D., Kopans, D., Evans, P., Monsees, B., Monticciolo, D., ... Burhenne, L. W. (2010).

Breast cancer screening with imaging: Recommendations from the society of breast imaging and the ACR on the use of mammography, breast MRI, breast ultra sound, and other technologies for the detection of clinically occult breast cancer. Journal of the American College of Radiology, 7(1), 18-27. doi:10.1016/j.jacr.2009.09.022

Monticciolo, D. L., Newell, M. S., Hendrick, R. E., Helvie, M. A., Moy, L., Monsees, B., . . Sickles, E. A. (2017). Breast cancer screening for a vera ge-risk women: Recommendations from the ACR commission on breast imaging. Journal of the American College of Radiology, 14(9), 1137-1143. doi:10.1016/j.jacr.2017.06.001

\section{American Cancer Society (ACS)}

Oeffinger, K. C., Fontham, E. T. H., Etzioni, R., Herzig, A., Michaelson, J. S., Shih, Y. T., .. Wender, R. (2015). Breast cancer screening for women at a verage risk: 2015 guideline update from the American cancer society. Jama, 314(15), 1599-1614. doi:10.1001/jama.2015.12783 
4. National Comprehensive Cancer Network (NCCN)

Bevers, T. B., Helvie, M., Bonaccio, E., Calhoun, K. E., Daly, M. B., Farrar, W. B., . . Kumar, R. (2018). Breast cancer screening and diagnosis, version 3.2018, NCCN clinical practice guidelines in oncology. Journal of the National Comprehensive Cancer Network: JNCCN, 16(11), 1362-1389. doi:10.6004/jnccn.2018.0083

\section{United States Preventive Services Task Force (USPSTF)}

Siu, A. L. (2016). Screening for breast cancer: U.S. preventive services task force recommendation statement. Annals of Internal Medicine, 164(4), 279. doi:10.7326/M15-2886 
Appendix L: Pre-and-Post Knowledge and Project Implementation Surveys

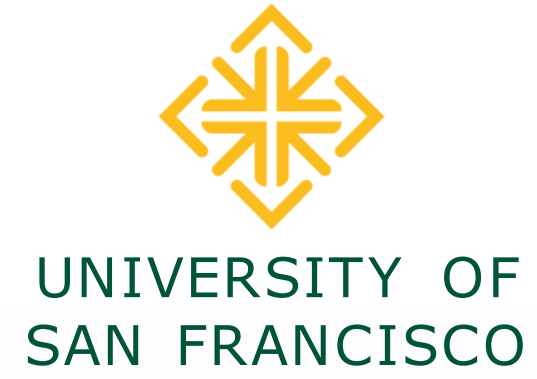

Breast Cancer Screening Pre Knowledge -Survey

1. How well do you understand current breast cancer screening protocol practiced at the Federally Qualified Health Center for average risk female patient's?

More than I would like About right Less than I would like

2. How well do you understand the current breast cancer screening protocol practiced at the Federally Qualified Health Center for high risk female patient's?

More than I would like About right Less than I would like

3. How well informed are you regarding the various guidelines for screening mammograms (ACOG, ACR, ACS, NCCN, USPSTF)?

Very well informed Somewhat well informed Not at all well informed

4. How important is it to you to counsel patients about mammogram screening guidelines to select individualized patient screening goals based on risk factors?

Very important Somewhat important Not at all important

5. How likely are you to implement an individualized screening protocol based on risk factors at this time?

Verylikely Somewhat likely Not at all likely

6. Comments/Feedback: 


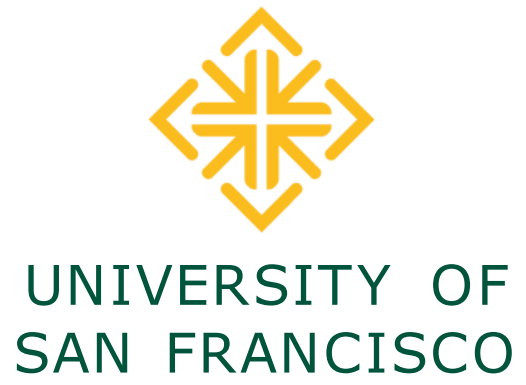

Breast Cancer Screening Post Knowledge -Survey

1. How well do you understand current breast cancer screening protocol practiced at the Federally Qualified Health Center for average risk female patient's?

More than I would like About right Less than I would like

2. How well do you understand the current breast cancer screening protocol practiced at the Federally Qualified Health Center for high risk female patient's?

More than I would like About right Less than I would like

3. How well informed are you regarding the various guidelines for screening mammograms (ACOG, ACR, ACS, NCCN, USPSTF)?

Very well informed Somewhat well informed Not at all well informed

4. How important is it to you to counsel patients about mammogram screening guidelines to select individualized patient screening goals based on risk factors?

Very important Somewhat important Not at all important

5. How likely are you to implement an individualized screening protocol based on risk factors at this time?

Verylikely Somewhat likely Not at all likely

6. Comments/Feedback: 


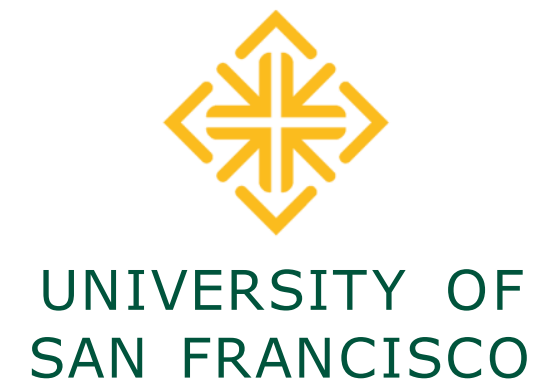

\section{Breast Cancer Screening Post Implementation Evaluation}

1. How comfortable did you feel using the Screening Mammogram Initiation Protocol?
Very comfortable
Somewhat comfortable
Not at all comfortable

2. How feasible has it been to incorporate during a women's annual exam?
Very feasible
Somewhat feasible
Not at all feasible

3. As a provider, using the SMIP tool, were you more engaged in making breast cancer screening decisions with your patients?
Yes
Somewhat
Not at all

4. As a provider do you see the value in initiating the SMIP protocol?
Yes
Somewhat
Not at all

5. Comments/Feedback? 
Appendix M: PowerPoint Slide Presentation
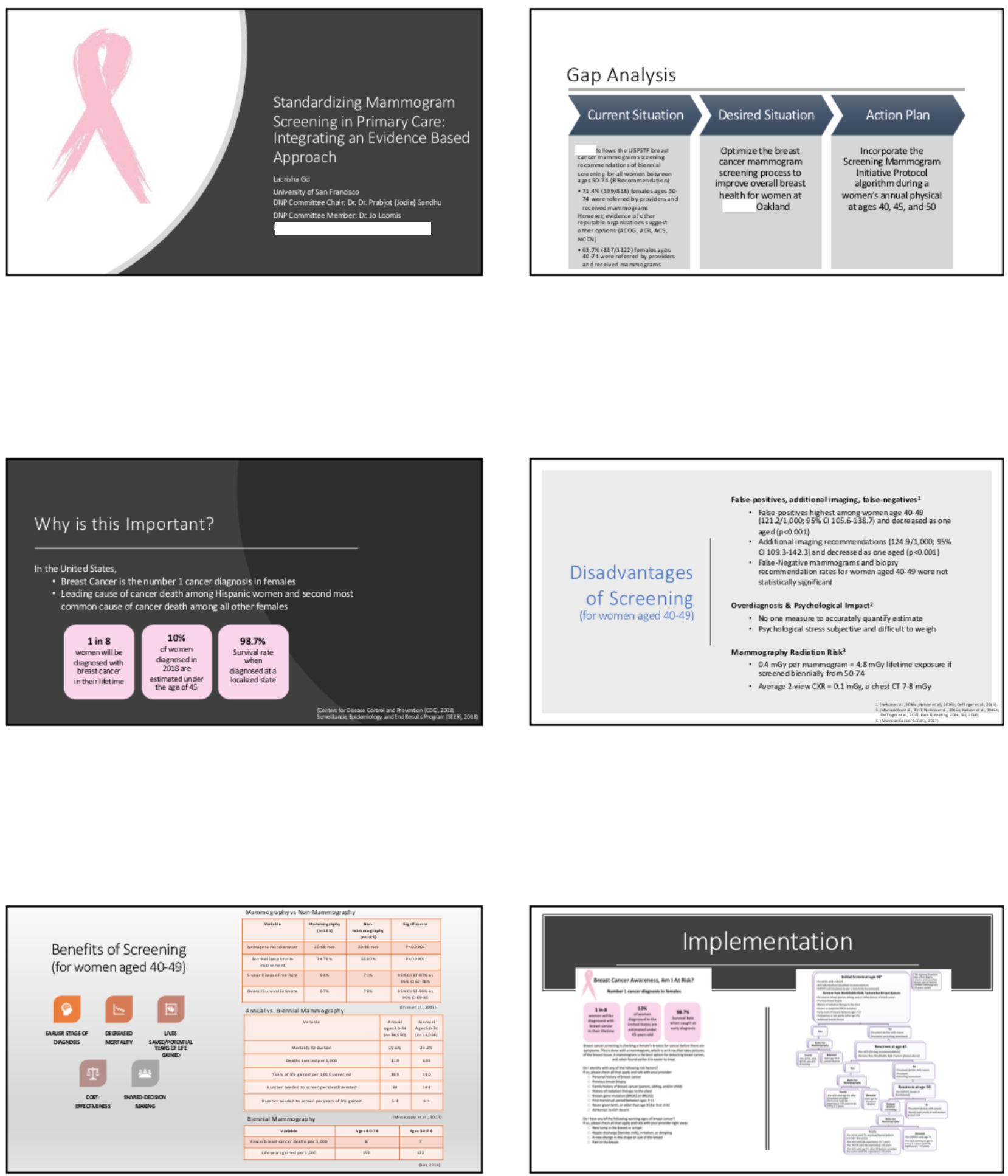

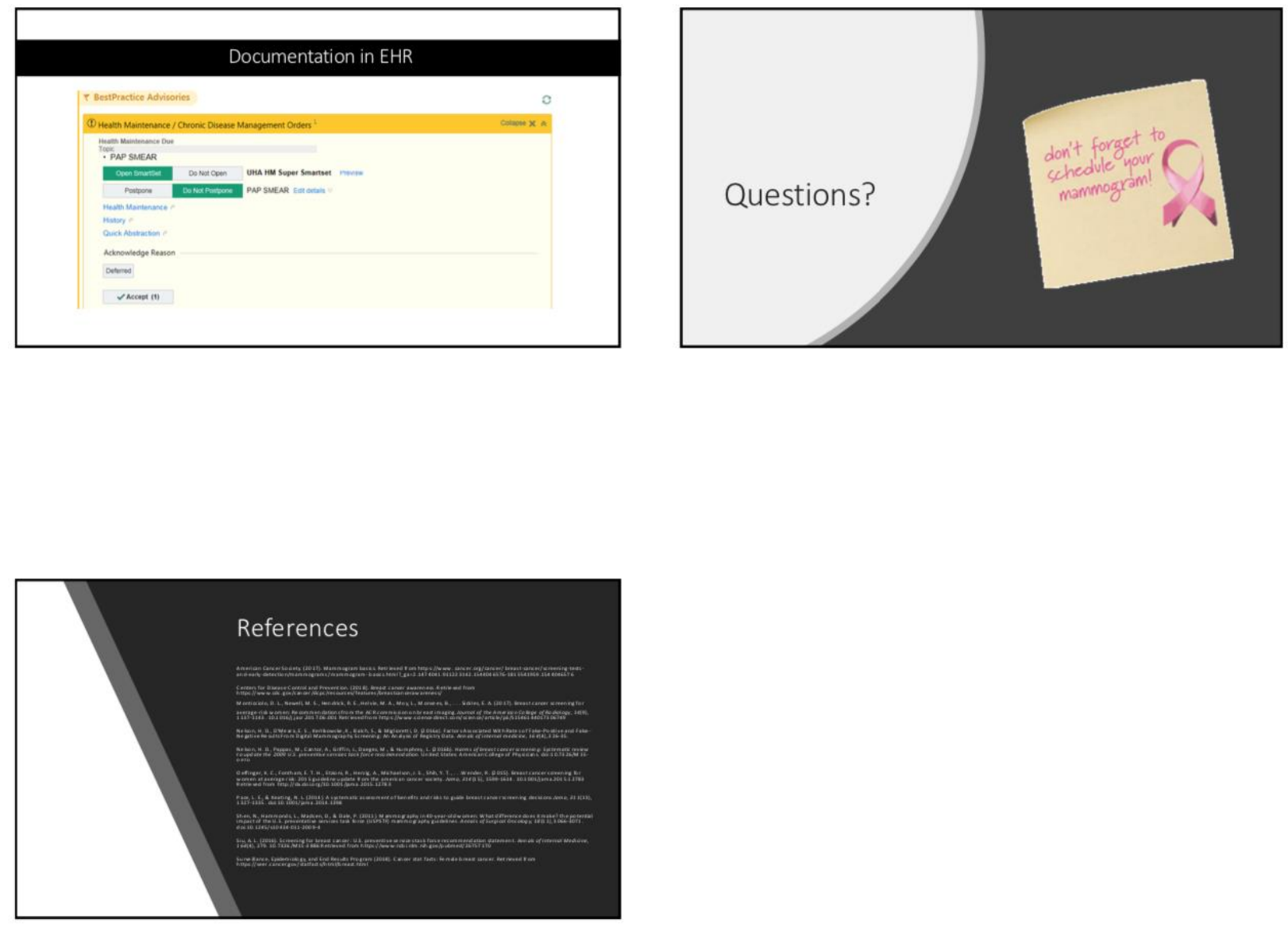
Appendix N: Survey Results

Pre/Post Knowledge Data

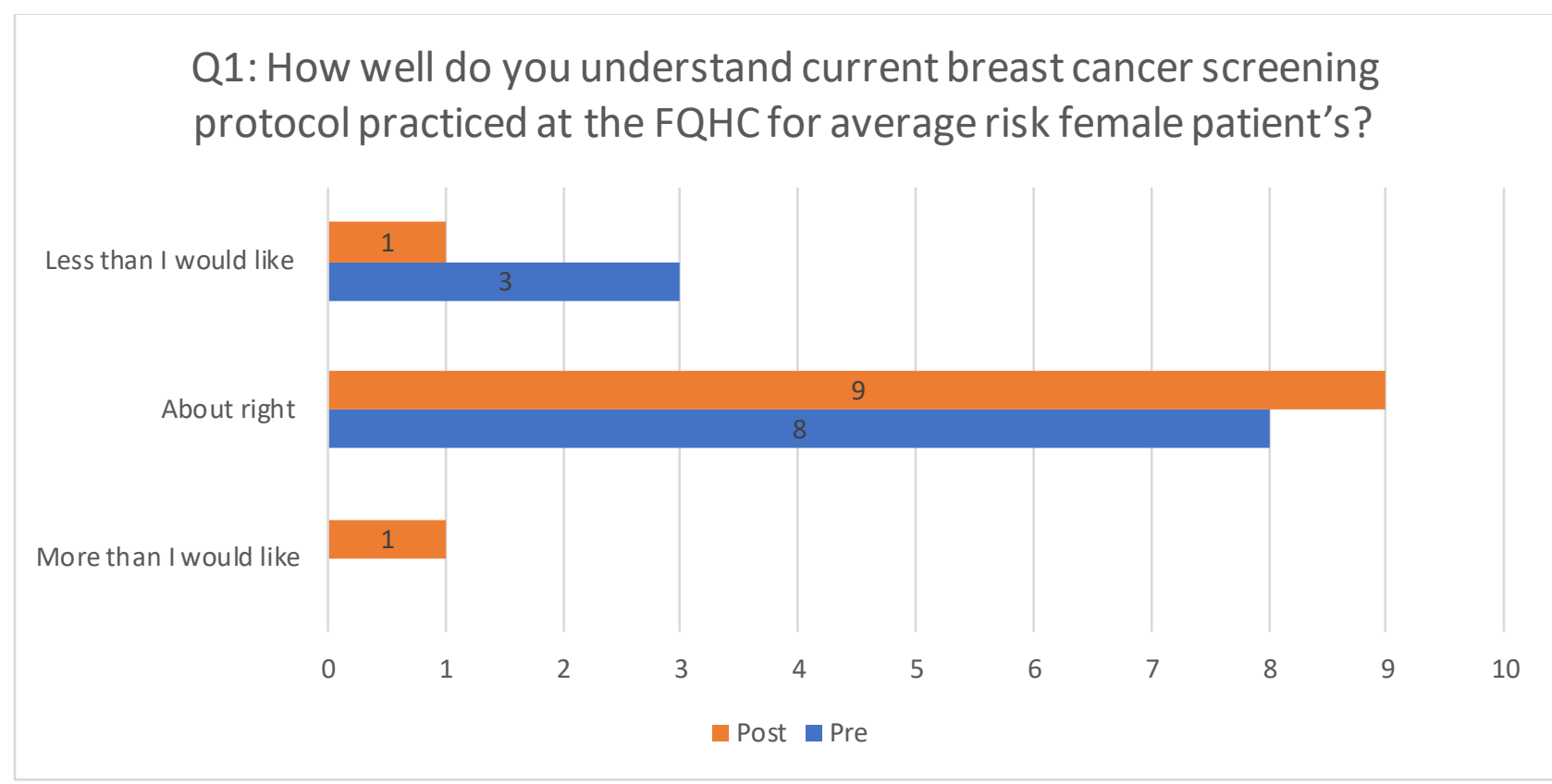

Q2: How well do you understand the current breast cancer screening protocol practiced at the FQHC for high risk female patient's?

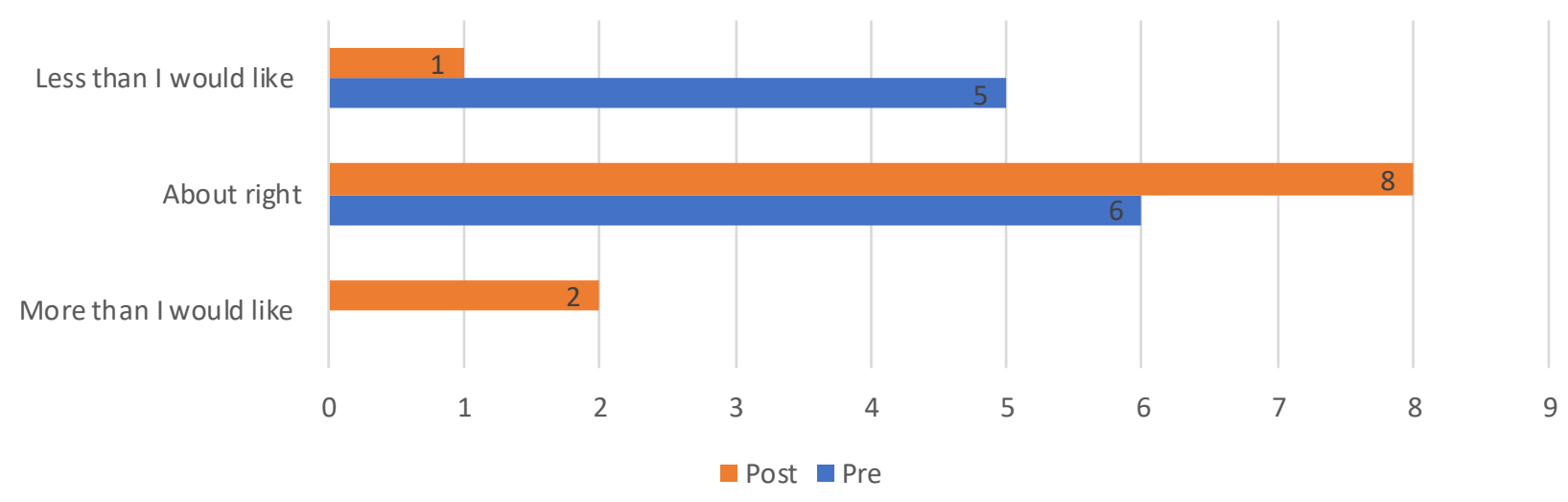


Q3: How well informed are you regarding the various guidelines for screening mammograms (ACOG, ACR, ACS, NCCN, USPSTF)?

Not at all well informed

Somewhat well informed

Very well informed

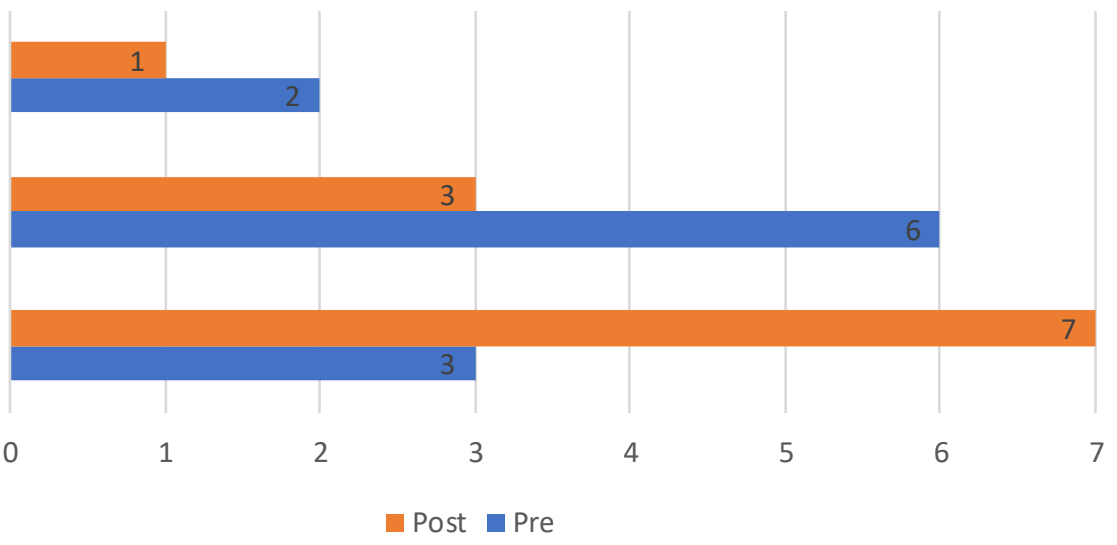

Q4: How important is it to you to counsel patients about mammogram screening guidelines to select individualized patient screening goals based on risk factors?

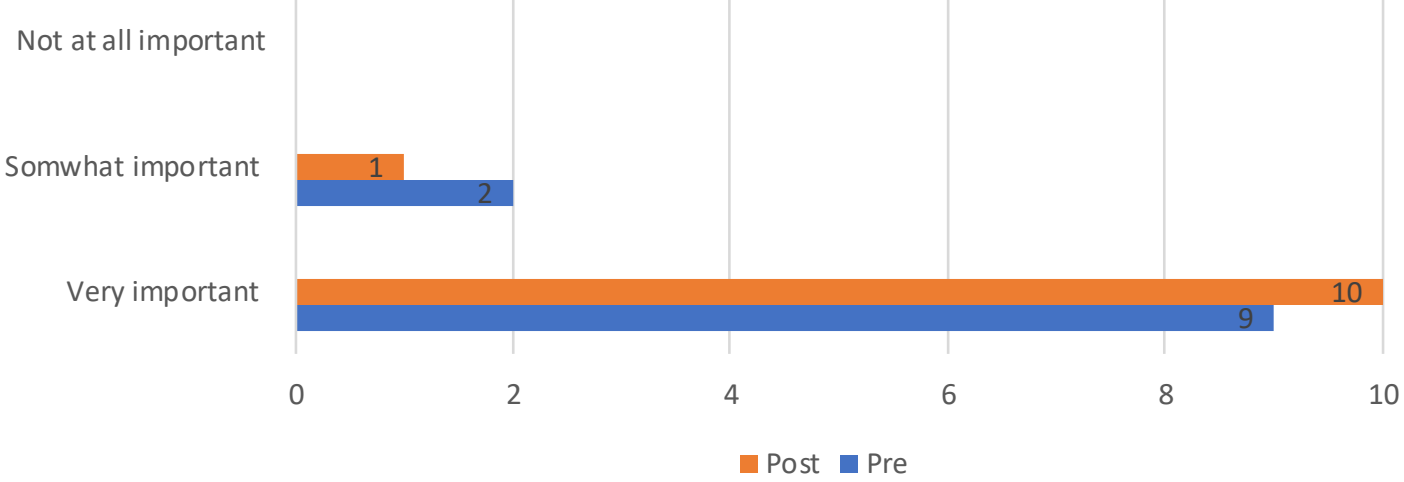


Q5: How likely are you to implement an individualized screening protocol based on risk factors at this time?

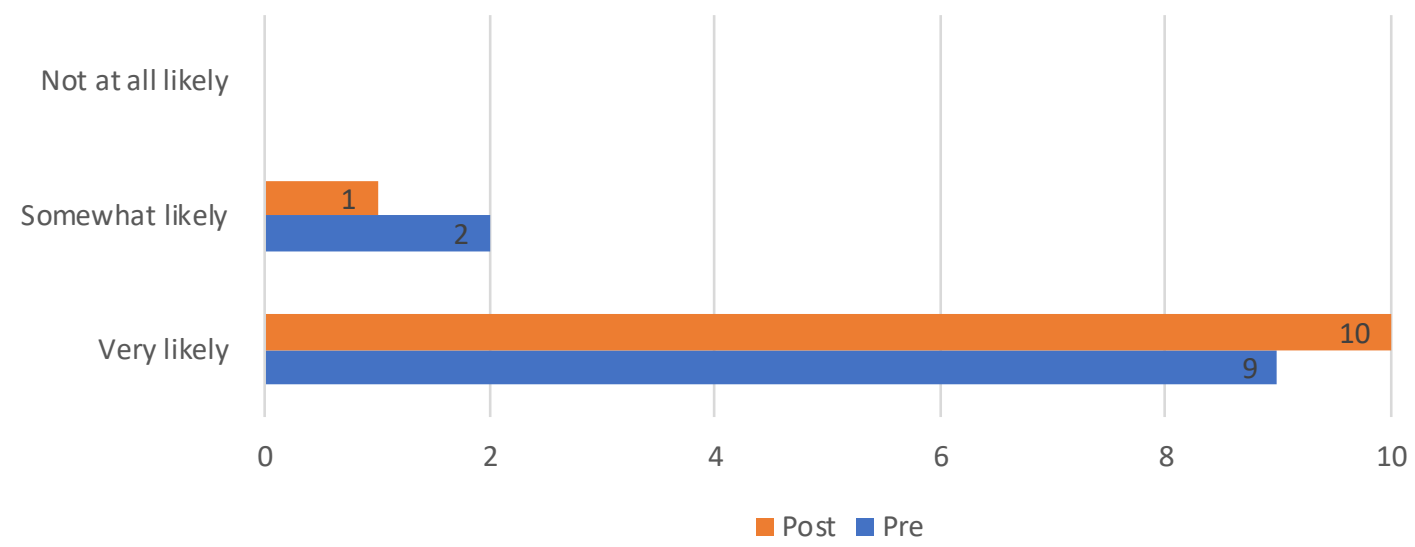

\section{Feedback Post-Education}

"Great work, I feel well informed after your lecture"

"Thanks :)"

\section{Post Implementation Data}

Q1: How comfortable did you feel using the Screening Mammogram Initiation Protocol?

9

8

7

6

5

4

3

2

1

0

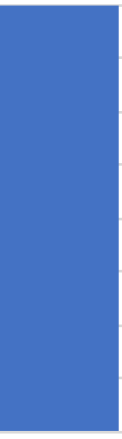




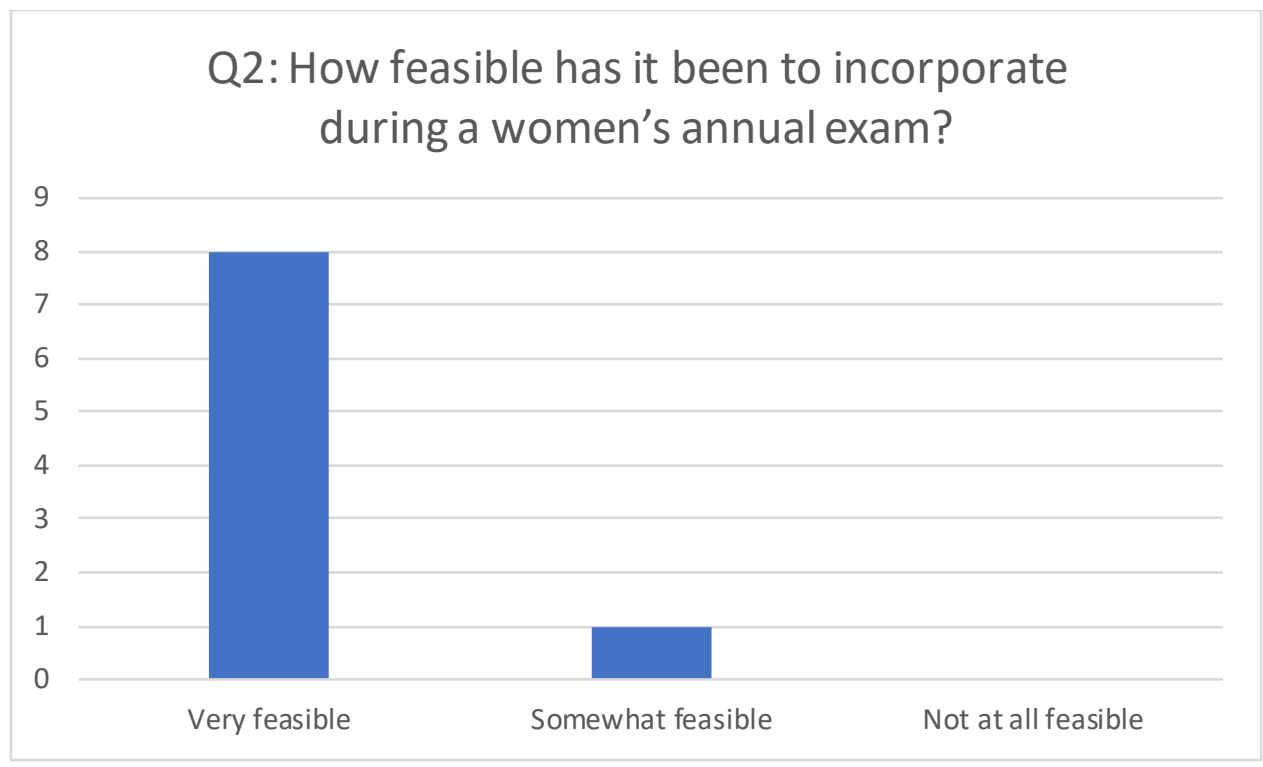

Q3: As a provider, using the SMIP tool, were you more engaged in making breast cancer screening decisions with your patients?

6

5

4

3

2

1

0

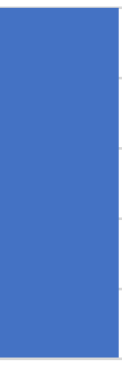

Yes

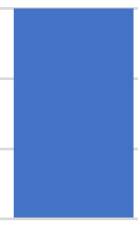

Somewhat

Not at all 


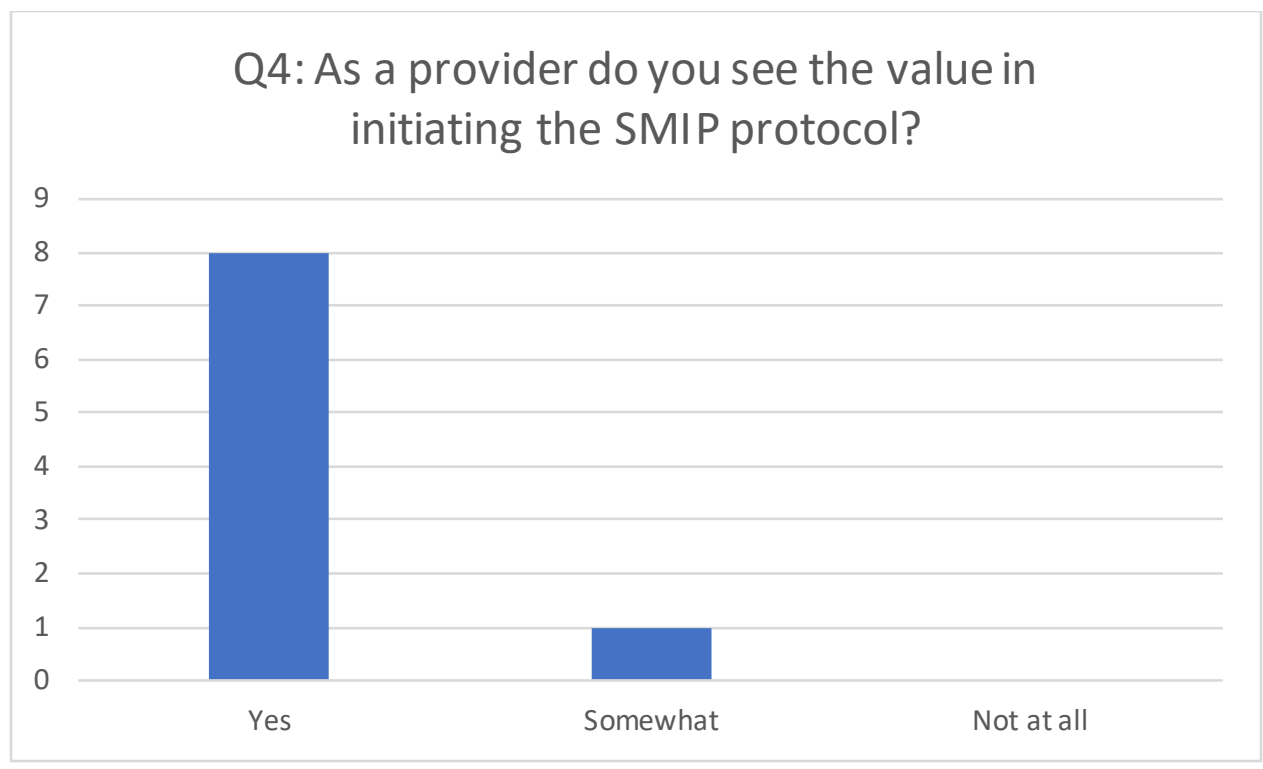

\begin{tabular}{|l|}
\hline Feedback Post-Implementation \\
\hline "I love laminated patient education tools!" \\
\hline "Great job! Go dons!" \\
\hline "Not sure if I'm really using this protocol, I use the USPSTF recommendations." \\
\hline "Great work! Great protocol." \\
\hline
\end{tabular}


Appendix O: I2I Tracking Results

9/10/17-9/10/18

\begin{tabular}{|l|l|l|l|}
\hline Age & $\begin{array}{l}\text { Number of eligible } \\
\text { participants }\end{array}$ & $\begin{array}{l}\text { Number referred by } \\
\text { provider }\end{array}$ & $\begin{array}{l}\text { Percent Screened } \\
\text { (Referred/Eligible) }\end{array}$ \\
\hline $40-49$ & 1334 & 863 & $64 \%$ \\
\hline $50-59$ & 841 & 617 & $73 \%$ \\
\hline
\end{tabular}

Project Implementation: 2/6/19-4/10/19 (9 weeks)

\begin{tabular}{|l|l|l|l|}
\hline Age & $\begin{array}{l}\text { Number of eligible } \\
\text { participants }\end{array}$ & $\begin{array}{l}\text { Number referred by } \\
\text { provider }\end{array}$ & $\begin{array}{l}\text { Percent Screened } \\
\text { (Referred/Eligible) }\end{array}$ \\
\hline $40-49$ & 842 & 609 & $72 \%$ \\
\hline $50-59$ & 555 & 445 & $80 \%$ \\
\hline
\end{tabular}

Women Ages 40-49 Referred for Mammography

$74 \%$

$72 \%$

$70 \%$

$68 \%$

$66 \%$

$64 \%$

$62 \%$

$60 \%$

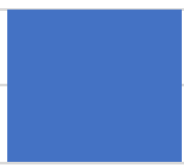

Pre-Project

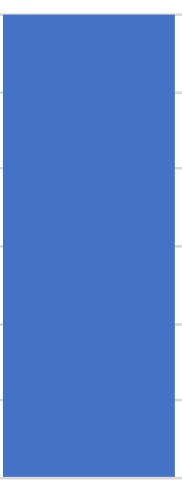

Post-Implementation

Women Ages 50-59 Referred for Mammography

$82 \%$

$80 \%$

$78 \%$

$76 \%$

$74 \%$

$72 \%$

$70 \%$

$68 \%$

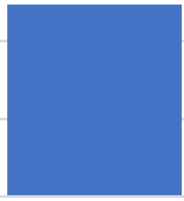

Pre-Project

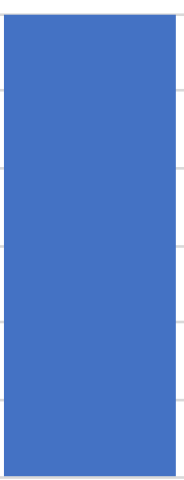

Post-Implementation 